\title{
De caballeros, animales y jaulas (II, 16-17): don Quijote y don Diego de Miranda entre vida política y vida literaria*
}

\author{
PIERRE DARNIS**
}

\author{
A Adrián J. Sáez, \\ soldado y compañero de investigación
}

\begin{abstract}
Resumen
Los capítulos 16-17 de la Segunda parte de Don Quijote encierran una sátira política y una sátira ad hominem. El personaje de don Diego forma parte de un amplio grupo de falsos caballeros, de los cuales don Quijote es la piedra de toque desde el capítulo 6. Dentro del itinerario menipeo de don Quijote, la indumentaria que viste el hidalgo de Miranda apunta a un blanco que muchos lectores del Siglo de Oro podían entrever. Además, dentro de un contexto militar que lleva a «proveer las costas de Nápoles y Sicilia y la isla de Malta» ante la amenaza del «Turco [que] bajaba con una poderosa armada» (II, 1), la figura del «caballero del verde gabán» se tornaba bastante controvertida.
\end{abstract}

Palabras clave: Cervantes; Don Quijote; Turco; Orán; Lope de Vega; caballero del verde gabán.

Title: On knights, animals and jails (II, 16-17): Don Quixote y Don Diego de Miranda between politic life and literary life

\footnotetext{
Abstract

Chapters 16-17 of the Second part of Don Quixote propose a political satire and an ad hominem satire. Don Diego is member of an ample group of false knights, of who don

* Este trabajo se enmarca en el proyecto de investigación SILEM, «El sujeto literario en la modernidad temprana» (MINECO FFI2014-54367-C2-1-R) dirigido por Pedro Ruiz Pérez.

** AMERIBER, Université Bordeaux Montaigne. pierre.darnis@u-bordeaux-montaigne.fr / ORCID iD: https://orcid.org/0000-0002-6901-0018.
} 
Quijote is the touchstone from chapter 6. Within the menipeo itinerary of don Quijote, the clothing that dresses the gentleman Miranda aims at a target that many readers of the Century of Gold could glimpse. In addition, in this thread to "made provision for the security of the coasts of Naples and Sicily and the island of Malta" before the threat of the "Turk [that] was coming down with a powerful fleet" (II, 1), the figure of the "knight of the green greatcoat" became enough controverted.

Keywords: Cervantes; Don Quixote; Turk; Oran; Lope de Vega; Knight of the Green Coat.

\section{Cómo citar este artículo / Citation}

Darnis, Pierre (2019). «De caballeros, animales y jaulas (II, 16-17): don Quijote y don Diego de Miranda entre vida política y vida literaria», Anales Cervantinos. 51, pp. 51-84, https://doi.org/10.3989/anacervantinos.2019.003.

... no tiene hoy día plaza en todo el ámbito de España que más le convenga celar y guardar, con la cual [...] ampara y asegura toda la costa meridional, y occidental de España, su mar e islas.

Diego Suárez Montañés, Avisos importantes para la Majestad del Rey ${ }^{* * *}$

\section{PRIMERA OBSERVACIÓN: PERSONAJES Y DEBATES}

Después del encuentro con un letrado disfrazado de caballero (el «de los Espejos», cap. 12-14), don Quijote y su amigo Sancho por fin descubren aparentemente a un caballero con todas las de la ley. Don Diego es el único personaje del Quijote que tiende a superar en dignidad al propio héroe. El título del primero de los tres capítulos $(16,17$ y 18) que este protagoniza lo define como «un discreto caballero de la Mancha». Miranda, a la inversa del «ingenioso» hidalgo, no parece adolecer de la ambivalencia discreto/loco que hace de don Quijote un personaje burlesco. Se inicia además esta secuencia manchega con el encomio pro domo sua del caballero rural, al cual van a suceder las alabanzas de un Sancho pasmado por tantas prendas ${ }^{1}$. Márquez Villanueva, sintetizando las distintas señas de identidad de don Diego, mostró

*** En Bunes Ibarra (2011: 31).

1. «Atentísimo estuvo Sancho a la relación de la vida y entretenimientos del hidalgo; y, pareciéndole buena y santa y que quien la hacía debía de hacer milagros, se arrojó del rucio, y con gran priesa le fue a asir del estribo derecho, y con devoto corazón y casi lágrimas le besó los pies una y muchas veces. Visto lo cual por el hidalgo, le preguntó:

-¿Qué hacéis, hermano? ¿Qué besos son éstos?

-Déjenme besar -respondió Sancho-, porque me parece vuesa merced el primer santo a la jineta que he visto en todos los días de mi vida» (II, 16: 755). Se cita el Quijote a partir de la edición dirigida por Francisco Rico (Cervantes 1998); para las coordenadas de las citas solo señalaré el libro, el capítulo y la página. 
que el caballero manchego se mueve por un ideal neoepicúreo hecho de beatus ille, carpe diem y aurea mediocritas:

[L]a personalidad que este otro caballero se ha forjado para sí con tanto éxito es por entero anticaballeresca, lo cual es lo mismo que antiaventurera. Frente al afán de gloria pregonada, que tanto satisface a don Quijote, el Verde Gabán se define como el más fiel discípulo de Epicuro en su máxima: «Vive de forma que nadie sepa que estás en el mundo» (2010: 185)².

La cuestión que divide a los comentaristas del episodio es la de saber si, para Cervantes y sus lectores, don Diego es un caballero más discreto que don Quijote. Por una parte, están los defensores del personaje principal del libro, que critican la indolencia de Miranda. Encontramos también por otra parte a los valedores de don Diego, como Emilio Martínez Mata, que percibe en el prudente hidalgo aburguesado la encarnación de un «modelo de vida» basado en la nobleza de quien "se dedica a hacer bien a los suyos», un modelo de la «preud'hommie» de Pierre Charron ${ }^{3}$. La voluntad de agresión al león en don Quijote, desde esta perspectiva, se puede definir a partir de las dos expresiones que la narración emplea: son «niñerías» y contraproducentes «bravatas» (II, 17: 766). En suma, los actos de don Quijote no serían «discretas locuras» (como explica sin embargo el prólogo, p. 621), sino muestras de locura.

Esta interpretación tiene cimientos muy sólidos. Como insiste Martínez Mata, la agresión a los leones no responde a ninguna de las cinco justificaciones de la guerra, según dirá luego don Quijote:

Los varones prudentes, las repúblicas bien concertadas, por cuatro cosas han de tomar las armas y desenvainar las espadas, y poner a riesgo sus personas, vidas y haciendas: la primera, por defender la fe católica; la segunda, por defender su vida, que es de ley natural y divina; la tercera, en defensa de su honra, de su familia y hacienda; la cuarta, en servicio de su rey, en la guerra justa; y si le quisiéremos añadir la quinta, que se puede contar por segunda, es en defensa de su patria. A estas cinco causas, como capitales, se pueden agregar algunas otras que sean justas y razonables y que obliguen a tomar las armas, pero tomarlas por niñerías y por cosas que antes son de risa y pasatiempo que de afrenta, parece que quien las toma carece de todo razonable discurso (II, 27: 859-860).

Atacando, pues, a los dos leones enjaulados, don Quijote se nos antoja un niño y, peor, un loco.

Con todo, resulta evidente que Cervantes favoreció la ambivalencia del pasaje y de los dos personajes. No solo el color verde característico del nuevo caballero reviste en la Segunda parte el sentido de las «decepciones y

2. Véase también el artículo de Álvarez (2007).

3. Martínez Mata (2015). Otros comentaristas, como J. Casalduero y A. Sánchez, subrayaron la personalidad positiva del "señor galán”, Percas de Ponseti (1975: 332-333). 
falsedades» que asedian a menudo a los dos héroes durante su tercera salida ${ }^{4}$, sino que la indirecta (repetida por don Quijote) que asocia a don Diego con un «perdigón manso» no es nada halagüeña (754 y 763). La metonimia supone además que por su dulce vida «caballeresca» Miranda se parece al león enjaulado. En estas líneas, en efecto, el «perdigón» no es el único macho enjaulado; el león también se encuentra en una jaula y, como es de notar, se mueve «con gran flema y remanso». Michel Moner, comentando el episodio, señaló así las tachas que la secuencia desvela en el personaje de don Diego:

En effet, non content d'abandonner don Quichotte à son sort -ce qui est déjà peu glorieux-, le chevalier ne se borne pas à prendre un peu de champ pour se mettre à l'écart: il s'enfuit aussi vite et aussi loin qu'il peut. Or, ce qui pourrait passer à nos yeux pour une prudence de bon aloi, ne saurait être admis sans réserves dès lors que l'on veut bien replacer l'aventure dans le temps où elle est censée se dérouler. Chacun sait, en effet, que l'on fait alors grand cas en Espagne du sentiment de l'honneur. Autant dire qu'aux yeux des contemporains de Cervantès, la fuite, pour un chevalier, fût-elle légitime, ne pouvait être qu'infamante [...]. Songeons que les nobles, même amollis par la vie à la cour, mettaient encore un point d'honneur à affronter le taureau sur la place publique, comme le rappelle, fort opportunément, don Quichotte: «Bien parece un gallardo caballero, a los ojos de su rey, en la mitad de una gran plaza, dar una lanzada con felice suceso a un bravo toro» (II, 17) .

Reducir la complejidad del episodio resulta sin duda un engaño ${ }^{6} \mathrm{y}$, a nivel científico, un sinsentido.

Si adoptamos además la visión del "discreto lector", la interpretación del pasaje se vuelve aún más compleja. Cuando se acalora don Quijote para combatir a los dos leones de Orán, los términos empleados por Cervantes hacen explícita referencia a la célebre distinción de Aristóteles (Ética a Nicomaco, III, 9-15) entre la virtud del valor y los tres defectos que la amenazan: la locura que le hace a uno ciego ante los peligros, la temeridad del fanfarrón y la cobardía del hombre apocado ${ }^{7}$.

Don Diego, como se ha visto, da muestras de miedo y deja traslucir su cobardía. En cuanto a don Quijote, su actitud parece colocarle en la posición del loco (una interpretación favorecida, desde luego, por la imagen de los requesones que salen de su celada como si fueran sus «sesos»): no «temen nada» los «locos», señala Aristóteles, y Cervantes sugiere lo mismo para su personaje principal.

4. Percas de Ponseti (1975: 386-395).

5. Moner (1986: 96).

6. También defiende Percas de Ponseti la naturaleza equívoca de las cualidades del Caballero «a lo verde» (1975: 334).

7. Sobre los polos opuestos a la valentía, Aristóteles no se limita al antagonismo del temerario y el cobarde. Introduce explícitamente el caso de los «locos»: «sería un loco o un insensible, si no temiera nada, ni los terremotos, ni las olas, como se dice de los celtas» (1985: 195). 
Profundizando un poco más en el nuevo juego de «Espejos» que propone el alter ego del «Verde gabán», se trasluce, sin embargo, que el defecto de comportamiento de don Quijote no es en realidad el de la locura:

Llegose en esto [al caballero del verde gabán] Sancho y díjole:

-Señor, por quien Dios es, que vuesa merced haga de manera que mi señor don Quijote no se tome con estos leones, que si se toma, aquí nos han de hacer pedazos a todos.

-Pues, ¿tan loco es vuestro amo -respondió el hidalgo-, que teméis, y creéis que se ha de tomar con tan fieros animales?

-No es loco -respondió Sancho-, sino atrevido.

-Yo haré que no lo sea -replicó el hidalgo.

Y, llegándose a don Quijote, que estaba dando priesa al leonero que abriese las jaulas, le dijo:

-Señor caballero, los caballeros andantes han de acometer las aventuras que prometen esperanza de salir bien dellas, y no aquellas que de todo en todo la quitan; porque la valentía que se entra en la juridición de la temeridad, más tiene de locura que de fortaleza. Cuanto más, que estos leones no vienen contra vuesa merced, ni lo sueñan: van presentados a Su Majestad, y no será bien detenerlos ni impedirles su viaje (II, 17: 762-763, la cursiva es mía).

La terminología empleada es transparente. Aunque Sancho le niega a su amigo la virtud del valor (de la fortaleza), don Diego no percibe más que a un «loco», desconociendo los verdaderos matices del sistema aristotélico, según los cuales don Quijote podría ser más bien el prototipo del temerario. Don Diego da muestras de imprecisión conceptual pues, en la controversia sobre la valentía, solo se considera loco a quien no le dan miedo las enfermedades, las tormentas, el hundimiento de su nave o la caída de un rayo ${ }^{8}$. En este contexto, la personalidad de don Quijote se aproxima al temerario más que al loco.

Podríamos terminar esta primera observación como si nos situáramos en medio de aquellas disputas que animaban las veladas de los contemporáneos de Miguel de Cervantes ${ }^{9}$ : delante de los leones, no es valeroso ni el temerario don Quijote, ni el cobarde don Diego. No obstante, este punto de vista implica pensar que Cervantes escribe como escolástico. Supone también que no tiene libertad de pensamiento y es un devoto de Aristóteles. Pero, ¿realmente para él la virtud se encuentra en el término medio? ¿No podemos pensar, al contrario, que en esta secuencia escribe como casuista?

El hecho es que Cervantes coloca a don Quijote ante un peligro mortal, lo que tiene la ventaja, según el esquema aristotélico, de permitir que se evalúe precisamente su valentía ${ }^{10}$. Da la impresión de que el autor sugiere en este

8. Ginés de Sepúlveda (2012: 92-93).

9. Darnis (2015b).

10. «Lo más temible es la muerte [...]. El cobarde, el temerario, el valiente, entonces, están en relación con las mismas cosas, pero se comportan de diferente manera frente a ellas», Aristóteles (1985: 194-196-1115a-). 
pasaje que el exceso, la temeridad, deben ser alabados en determinados casos, y esto en contra de la doxa promovida por el antiguo filósofo: el «animoso don Quijote de la Mancha» sí que puede equipararse con un «espejo donde se pueden mirar todos los valientes del mundo» (765). Recordemos que Cervantes, por mucho que sufriera de «calenturas» durante la batalla de Lepanto, aseguró (¿cómo loco?) que su presencia «en el lugar del esquife» no sería inútil para combatir al Turco y ayudar a que triunfara la Santa Liga frente a los avances otomanos en el Mediterráneo ${ }^{11}$. En todo caso, vencieron las galeras cristianas, y don Juan de Austria, que las capitaneaba, tuvo luego a Cervantes «en mucha reputación» por su acción temeraria ${ }^{12}$.

Me parece, además, que la presencia de banderas reales debe obligarnos a considerar la presencia de estos animales como un caso concreto que por ello merece una interpretación coyuntural. Si hoy día esta fórmula general de la temeridad virtuosa tal vez suene absurda, es probablemente porque nuestro sistema de valores ha cambiado ${ }^{13}$. Pero cabe añadir también otra razón, de índole hermenéutica: no resulta fácil advertir ahora todas las señales oblicuas que Cervantes dispuso en el relato.

\section{SEGUNDA OBSERVACIÓN: EL OBJETO DE ESTUDIO, LA OBRA COMO CONJUNTO}

Un primer sesgo científico a la hora de entender el Quijote es paradójicamente el método del análisis, es decir, la dificultad de conseguir una perspectiva sintética ${ }^{14}$. En una obra narrativa, la perspectiva sintética se puede llamar memoria del texto leído. Por ello, si bien un investigador no debe imitar a Funes el Memorioso, el personaje que inventó Borges, al menos aquel debe recordar lo que ha leído antes al llegar al episodio de los leones.

Recordemos, por ejemplo, la primera etapa del viaje de los dos compañeros de la Mancha, la del Toboso. Si nos fijamos en los detalles del episodio nocturno, observamos que además de Dulcinea, lo que busca don Quijote son «ricos y reales palacios» (II, 8: 687). Esta idea es totalmente coherente con lo que sabemos desde el principio del libro, ya que lo que se persigue es reunir la flor y nata de la caballería. Dirigiéndose hacia el Toboso, el hidalgo piensa acercarse al poder sociopolítico. El proyecto cervantino ha cambiado entre la Primera y la Segunda parte. Ahora, antes que mostrar la fuerza de su brazo, lo que pretende don Quijote es encontrar a los auténticos protectores

11. Sliwa (2006: 265), citando a Rodrigo de Cervantes, que «presentó un pedimento y cuestionario de preguntas sobre los servicios de su hijo, Miguel de Cervantes».

12. Sliwa (2006: 358).

13. Sobre el cambio de paradigma histórico, Koselleck (1990).

14. En el Quijote, «no tiene interés político uno u otro episodio concreto, una u otra frase aislada. Cervantes intenta toda una empresa con unidad de sentido a través de la total aventura de don Quijote», Maravall, citado por Insua Rodríguez (2017: 38). 
de la Monarquía hispánica. En 1615, ir en busca de Dulcinea (no se debe olvidar que es una «princesa») se presenta en suma como un pretexto para su búsqueda y petición de «principalidad» (688), de personajes «principales».

¿Sería este deseo de encontrar noblezas un capricho vano y, desde el punto de vista libresco, un motivo de parodia? Sí, por supuesto. Pero ¿solo lo concebían de forma jocosa los lectores de la modernidad temprana como un mero ingrediente de entretenimiento entre otros muchos?

Antes de juzgar apresuradamente, quizá debamos recordar, como cualquier discreto lector del momento, las primeras etapas del libro, esto es, los capítulos que a veces se van marginando para privilegiar los debates sobre la calidad «literaria» de la Primera parte.

a) El contexto ficcional que enmarca las andanzas del «caballero» es el que fija el cura en el primer capítulo, y tiene fundamentos empíricos tanto en la experiencia previa de Cervantes en Lepanto como con las inquietudes políticas de principios del XVII: el peligro de la «bajada» del «Turco [...] con una poderosa armada» (II, 1: 627).

b) Esta sensibilidad hacia los «asuntos exteriores» es, muy explícitamente, lo que vuelve a excitar y despertar la manía caballeresca del hidalgo y le otorga su nueva misión: reunir a los auténticos caballeros de la Monarquía hispánica (los llamados «verdaderos» caballeros). ¿Qué propuso el hidalgo en el primer capítulo para responder a las inquietudes bélicas y militares del cura Pero Pérez? ¿No dijo acaso que debía «mandar Su Majestad por público pregón que se junten en la corte para un día señalado todos los caballeros andantes que vagan por España; que, aunque no viniesen sino media docena, tal podría venir entre ellos, que solo bastase a destruir toda la potestad del Turco?» (628-629). Y luego insiste el hidalgo: «[d]estos [caballeros] o tales como estos quisiera yo que fueran los de mi arbitrio, que, a serlo, Su Majestad se hallara bien servido y ahorrara de mucho gasto, y el Turco se quedara pelando las barbas; y con esto no quiero quedar en mi casa» (635, la cursiva es mía). Ahora sí, don Quijote tiene un motivo para dejar su «aposento», como, años antes, lo tuvo don Miguel cuando se encontraba todavía en Roma...

En esta fantasía literaria, los discretos lectores del momento podían reconocer no solo una imitación del primer canto del célebre poema narrativo de Torquato Tasso, La Jerusalén liberada, sino también la peligrosa y controvertida «jornada de Argel», que en los años de la escritura y publicación de la Segunda parte, la Monarquía de Felipe III sigue preparando ${ }^{15}$.

c) El relato del Ingenioso caballero se vertebra, en consecuencia, en torno a un programa desvelador que expone muy precisamente el capítulo 6 :

Ni todos los que se llaman caballeros lo son de todo en todo: que unos son de oro, otros de alquimia, y todos parecen caballeros, pero no todos pueden estar al toque de la piedra de la verdad. Hombres bajos hay que revientan por parecer caballeros, y caballeros altos hay que parece que aposta mueren

15. Véase Darnis (2016b). 
por parecer hombres bajos; aquéllos se levantan o con la ambición o con la virtud, éstos se abajan o con la flojedad o con el vicio; y es menester aprovecharnos del conocimiento discreto para distinguir estas dos maneras de caballeros, tan parecidos en los nombres y tan distantes en las acciones (II, 6: 674).

Dentro de este propósito desmitificador, el personaje de don Quijote constituye para Cervantes y sus lectores la «piedra [de toque] de la verdad», la que desvelará la falsa caballerosidad de tal o cual noble. El proyecto que estructura la Segunda parte resulta, pues, diáfano. Don Quijote, concebido como auténtico kataskopos y agudo espía menipeo a la manera de Lucio en el Asno de Luciano de Samosata o Guzmán en la Atalaya de Mateo Alemán, sirve a Cervantes para pasar revista a cuantas formas de nobleza caballeresca pueblan la península ibérica. Obviamente, para leer bien el segundo Quijote, las unidades de medida de los críticos deberán integrar al menos las que correspondían a la estrategia militar del héroe y que tenía el propio Cervantes cuando quiso integrar los Tercios con objeto de alejar a la armada otomana y sus aliados berberiscos de las costas de la Monarquía hispánica, es decir, las ibéricas, pero también las italianas del Reino de Nápoles y las muy aisladas de Malta que albergaban a los caballeros de San Juan.

Dentro de la secuencia que estamos analizando, el problema es, por tanto, la integración del personaje de don Diego dentro del recorrido de lectura programado por Cervantes desde el marco interpretativo de los primeros capítulos. Si, como dice Sancho, Miranda es un «santo a la jineta», dicha perfección debe también ajustarse a la «verdadera caballerosidad» que exigen los tiempos de tensión mediterránea a la Monarquía hispánica. Como buen maestro de ceremonias, Cervantes va a introducir en los capítulos 16 y 17 una situación que se anunciaba en el primero: un momento que evidenciará si el llamado «caballero» (en este caso don Diego de Miranda) puede o no «estar al toque de la piedra de la verdad», el de la irrupción de los leones, es decir, el animal que mejor permite acercarse a una prueba caballeresca tradicional.

Al leer con rigor la Segunda parte, son varios los críticos que han llamado la atención asimismo sobre la asombrosa acumulación de referencias bélicas, desde la referencia inaugural de la bajada del Turco hasta la invasión semiburlesca de Barataria ${ }^{16} \mathrm{y}$, luego, el ataque totalmente serio realizado en Barcelona por dos turcos contra las galeras mediterráneas de la Corona. Como puntualizaron algunos ${ }^{17}$, Cervantes ha multiplicado en el texto de 1615 los motivos ficcionales que apuntan a amenazas militares ${ }^{18}$ de forma más o menos jocoseria.

En el caso preciso del ataque al gobierno de Barataria, la incompetencia palmaria de Sancho en lo militar sirve para demostrar la importancia platóni-

16. II, 53: «Han entrado infinitos enemigos en la ínsula» (1062).

17. Moner (1986) y Cascardi (2012: 51)

18. Últimamente: Higuera (1995), Layna Ranz (2005: 192-194) y Darnis (2016a: 71-236). 
ca de la aptitud militar para los Estados ${ }^{19}$. Es paradójicamente en este momento burlesco del libro (y en vísperas de la futura utilidad de la atalaya barcelonesa) cuando Cervantes saca a relucir, en conformidad con el discurso sobre las Armas y las Letras (I, 38), la legitimidad que tendría el soldado don Quijote $^{20}$.

Sancho, modelo de estadista manso e imprudente, reconoce que le falta el brazo militar de su compañero: «¿Qué me tengo de armar [...], ni qué sé yo de armas ni de socorros? Estas cosas mejor será dejarlas para mi amo don Quijote, que en dos paletas las despachará y pondrá en cobro; que yo, pecador fui a Dios, no se me entiende nada de estas priesas» (II, 53: 1062). A la luz lucianesca de Barataria, el temerario hidalgo deviene el emblema menipeo y jocoserio del ideal de defensa de la república.

\section{TERCERA OBSERVACIÓN: LECTURA SUPERFICIAL Y SIMBOLOGÍA}

Otro enfoque complementario que se puede sugerir a la hora de estudiar las obras de la Modernidad temprana es el de la lectura superficial ${ }^{21}$. Antes de dejarnos llevar por una glosa embriagadora del Quijote, fijémonos en los muchos detalles que ha dispuesto Cervantes para que veamos claramente el sentido de la fábula.

Empecemos por la precisión célebre del gabán verde con que Cervantes viste a su «discreto caballero». Como otros críticos, no creo que este elemento plantee demasiadas dificultades interpretativas ${ }^{22}$; el indicio forjado por Cervantes se concibió como un símbolo que muchos lectores del momento podían descifrar sin dificultad.

Una primera pista es quizá la consecuencia bastante paradójica que provoca la «santidad» epicúrea y pacífica de este personaje. Al salir de la casa del caballero del verde gabán y antes de dirigirse hacia Zaragoza, don Quijote prefiere tomar un desvío por la «cueva de Montesinos» y los territorios de «Ruidera ${ }^{23}$. La referencia a estos espacios servía para que los lectores corroboraran su lectura «seria» de don Quijote (por lo menos en esta fase del relato). Dirigiéndose hacia una sima conocida por su pasado legendario y su relación con la «caza de Roncesvalles», don Quijote empieza a dar a su viaje

19. Cascardi (2012).

20. Insua (2017: 43)

21. Véase, por ejemplo, Darnis (2015c).

22. Por ejemplo, Bernis (1959).

23. Cervantes (1998: 780): «Cuatro días estuvo don Quijote regaladísimo en la casa de don Diego, al cabo de los cuales le pidió licencia para irse, diciéndole que [...] se quería ir a cumplir con su oficio, buscando las aventuras, de quien tenía noticia que aquella tierra abundaba, donde esperaba entretener el tiempo hasta que llegase el día de las justas de Zaragoza, que era el de su derecha derrota; y que primero había de entrar en la cueva de Montesinos, de quien tantas y tan admirables cosas en aquellos contornos se contaban, sabiendo e inquiriendo asimismo el nacimiento y verdaderos manantiales de las siete lagunas llamadas comúnmente de Ruidera» (II, 18, la cursiva es mía). 
un acusado sentido carolingio. En vez de alejarlo de su ideario belicista, el «manso» don Diego ha inducido a don Quijote a reforzarlo y a acercarle más a la gesta de los caballeros de Carlomagno.

Tanto es así que, después del indicio de Montesinos, el de Ruidera consolida tal hipótesis. Los lectores de Cervantes bien podían captar la alusión respetuosa a los Caballeros de San Juan ${ }^{24}$. Esta orden de caballería «extranjera» no solo era la única reconocida en la península ibérica, sino que tenía la función de proteger la isla de Sicilia después de la caída de Trípoli en $1551^{25}$. Cervantes debió de conocerla bastante pues tuvo contactos personales con al menos tres de sus caballeros: Juan Bautista Ruiz de Vergara, que murió durante el asalto berberisco a la galera Sol, y don Antonio de Toledo y don Francisco de Valencia, que fueron compañeros suyos de cautiverio en Argel $^{26}$. La decisión de pasar por la jurisdicción señorial de Ruidera, símbolo espacial de «reconquista», resulta lógica si nos acordamos de los detalles del atavío de don Diego, en perfecta sintonía con el color verde del gabán:

Traía un alfanje morisco [es decir, un sable pequeño] pendiente de un ancho tflí de verde y oro, y los borceguíes eran de la labor del tahalí; las espuelas no eran doradas, sino dadas con un barniz verde, tan tersas y bruñidas que, por hacer labor con todo el vestido, parecían mejor que si fuera de oro puro (II, 16: 751).

En el imaginario de la Segunda parte recorrido por la mitología de Roncesvalles $^{27}$, los símbolos caballerescos del noble son bastante equívocos.

24. Las palabras de Montesinos confirmarán el indicio del capítulo 18: «Aunque pasan de quinientos -explica Montesinos-, no se ha muerto ninguno de nosotros [los amigos de Durandarte]: solamente faltan Ruidera y sus hijas y sobrinas, las cuales llorando, por compasión que debió de tener Merlín de ellas, las convirtió en otras tantas lagunas, que ahora, en el mundo de los vivos y en la provincia de la Mancha, las llaman las lagunas de Ruidera; las siete son de los reyes de España, y las dos sobrinas, de los caballeros de una orden santísima, que llaman de San Juan» (Cervantes 1998, II, 23: 821-822).

Darnis (2016a: 192-197): «Passer par les lagunes de Ruidera, sous la juridiction du roi et de l'ordre de Saint Jean de Jérusalem est une action dense sur le plan symbolique. Lorsque Cervantès dirige son héros vers la grotte de Montesinos, il l'associe aux guerriers carolingiens. Ce faisant, il ramène les soldats de Charlemagne au seuil de la réalité contemporaine, puisque parmi les terres de Ruidera, certaines sont placées sous la juridiction du roi Philippe III, d'autres sous la responsabilité de l'ordre de Malte (le fort de Ruidera, en particulier, était aux mains des Hospitaliers depuis 1215). Or ces deux institutions développaient conjointement leur lutte contre la galaxie de la Sublime Porte dans la Méditerranée occidentale grâce aux galères royales et, dans la partie orientale, avec l'appui des chevaliers de Saint-Jean de Jérusalem (et de Malte) qui menaient des attaques ponctuelles contre les navires ottomans»).

25. Sobre el objetivo protector de los territorios occidentales de la Monarquía hispánica por los caballeros de Malta: Jiménez Moreno (2011: 316, 331-332).

26. Ver Gonzalo Sánchez-Molero (2010).

27. Recuérdese el augurio inicial en el Toboso: «Estando los dos en estas pláticas, vieron que venía a pasar por donde estaban uno con dos mulas, que, por el ruido que hacía el arado, que arrastraba por el suelo, juzgaron que debía de ser labrador, que habría madrugado antes del día a ir a su labranza; y así fue la verdad. Venía el labrador cantando aquel romance que dicen: "Mala la hubistes, franceses, / en esa de Roncesvalles"». 
Visto desde la perspectiva de su héroe y de sus recuerdos medievales de la España bajo dominio musulmán, el «caballero del verde gabán» bien se parece a un sarraceno.

El conocimiento del Romancero debió de favorecer en los lectores esta interpretación. Dentro del ciclo poético de Carlomagno, que integra al personaje de Montesinos, eran los enemigos del emperador quienes llevaban la vestimenta y el alfanje de don Diego. Más aún, es Calaínos, el amante de la hija del rey moro de Zaragoza (citado por Sancho en el capítulo 9) quien luce por definición un «alfanje»: este tipo de sable, que se asocia metonímicamente con los soldados moros, turcos y berberis $\cos ^{28}$ por oposición a la espada cristiana, debía servir para matar (en vano) a Orlando en la famosa obra de Ariosto $^{29}$. Históricamente además, el alfanje puede también asociarse con el que blandió el rey de Argel Hassán Bajá para mostrar a su ejército cómo luchar contra los soldados de Orán ${ }^{30}$.

Podemos pues imaginar que Cervantes dispuso el alfanje y el «tahalí» (otro signo redundante) para fortalecer el simbolismo político-cultural del color verde lucido por don Diego ${ }^{31}$.

\section{CUARTA OBSERVACIÓN: LA LECTURA SINCRÓNICA}

Hace ya casi un siglo, en Ficciones, Jorge Luis Borges recomendaba varias estrategias críticas. Harto conocido y citado es el método de la reinterpretación del Quijote a la luz de las coordenadas de la época de Pierre Menard. Para este autor ficticio de principios del siglo XX, la mejor comprensión del libro

-Que me maten, Sancho -dijo, en oyéndole, don Quijote-, si nos ha de suceder cosa buena esta noche. ¿No oyes lo que viene cantando ese villano?

-Sí oigo -respondió Sancho-; pero, ¿qué hace a nuestro propósito la caza de Roncesvalles? Así pudiera cantar el romance de Calaínos, que todo fuera uno para sucedernos bien o mal en nuestro negocio», Cervantes (1998, II, 9: 698). Sobre la dimensión programática del augurio tobosino y carolingio: Darnis (2016a: 113-135) y Darnis (2018).

28. Véanse, por ejemplo, en La Galatea «los bárbaros alfanjes y parecerse las blancas tocas de la turca gente» (2014: 119).

29. «[El Moro] sacó un alfanje muy rico / para habelle de matar [a Calaínos]». Recuérdese que al principio de El gallardo español, un vigía da la voz de alarma cuando ve a «un moro [... que] adarga blanca trae, y alfanje al lado», Cervantes (2015: 26, v. 135-140). Redondo recuerda lo que dice Sancho en el Quijote del seudo-Avellaneda: «Sur le vêtement typique du Maure: $c f$. Avellaneda, Segundo tomo, "si él fuera pagano, claro está que estuviera vestido como moro, de colorado, verde o amarillo, con su alfanje y turbante"», Redondo (1998: 269).

30. Mármol Carvajal (1573: fol. 106r): «Mas [, luego,] era tanto el temor que tenían que duró poco el asalto, y luego se retiraron».

31. Sobre el color verde como símbolo de raigambre musulmán: Márquez Villanueva (2010: 145). Percas de Ponseti subraya por su parte la importancia de los «borceguíes»: «El borceguí, informa Covarrubias, es una "bota morisca" usada de jinetes y en particular de "moros". El cautivo que entra en la posada, en la Primera parte, "traía unos borceguíes datilados y un alfanje morisco, puesto en un tahelí que le atrevesaba el pecho". Lo que en este personaje que huye de Argel es atavío propio del trance en que se halla, en don Diego de Miranda [...] resulta indumentaria insólita» (1975: 336). 
de Cervantes es la que ofrece una lectura separada de su contexto de origen, la lectura ultracontemporaneísta, tan apreciada por autores como Miguel de Unamuno y José Ortega y Gasset.

Pero este estrafalario comentarista, antes de dejarse seducir por la magia de un enfoque que los historiadores censuran ahora acusándolo de presen$t_{i s m o}{ }^{32}$, había sido tentado anteriormente por otro método, el del historicismo. El pasaje, generalmente obviado, presentaba un procedimiento muy interesante:

El método inicial que imaginó era relativamente sencillo. Conocer bien el español, recuperar la fe católica, guerrear contra los moros o contra el turco, olvidar la historia de Europa entre los años de 1602 y de 1918, ser Miguel de Cervantes. Pierre Menard estudió ese procedimiento [...] pero lo descartó por fácil [...]. Ser en el siglo veinte un novelista popular del siglo diecisiete le pareció una disminución. Ser, de alguna manera, Cervantes y llegar al Quijote le pareció menos arduo — por consiguiente, menos interesante - que seguir siendo Pierre Menard y llegar al Quijote, a través de las experiencias de Pierre Menard ${ }^{33}$.

El «método inicial» de Menard, que recuerda el elogio borgesiano a Edward Gibbon ${ }^{34}$, puede ser, por oposición al segundo, lúdico y fantasioso, mucho más científico de lo que parece. Pero ¿qué implica entonces, en el extraño episodio de los leones, esta lectura sincrónica?

Lo que cuesta reconocer en un libro que anacrónicamente algunos consideran únicamente «literario» (como quizá los aficionados del segundo método de Pierre Menard), es la impronta ideológica de determinados episodios. De hecho, los lectores de principios del Seiscientos debieron de percibir que la terminología sobre la fortaleza no solo implica un anclaje aristotélico, sino que el ethos y discurso de don Quijote entroncan, por su parte, con el ideario del muy polémico Juan Ginés de Sepúlveda.

El humanista era el gran defensor de la vida activa frente a cuantos religiosos reaccionarios y cuantos humanistas vanguardistas sostenían la mansedumbre sistemática en las relaciones políticas ${ }^{35}$. En su lucha contra la teoría antigua de la primacía de la vida contemplativa representada por el clero regular, convenía valorar para Ginés de Sepúlveda los esfuerzos de los soldados. Esto con el objetivo de que la población protegida y los responsables políticos

32. Sobre este concepto: Hartog (2003).

33. Borges (1998: 47-48).

34. Véase Fuentes Vázquez (2007: 303-312).

35. Véase, en particular, el Democrates primus, de 1535, que tuvo una traducción al castellano en 1541 y que nutrió ideológicamente las milicias europeas en defensa del valor bélico. Para Ginés de Sepúlveda, la «osadía» (o temeridad) es necesaria en los combates: «Para discernir todas estas cosas una regla certísima nos es dada por los sabios, la cual debemos guardar y diligentemente seguir, conviene a saber, que aquel digamos valiente que en los peligros de muerte [de las guerras justas] osa» (2012: 93). Sobre la importancia del humanista, es fundamental el trabajo de Castilla Urbano (2013). Sobre su impronta probable en Cervantes: Higuera (1995: 51-69); Darnis (2016a: 291-294); Insua Rodríguez (2017: 57-95). 
(cada vez más «caballeros» ${ }^{36}$ ) reconocieran la legitimidad social y espiritual del deseo de «gloria» mundana de los guerreros ${ }^{37}$. Lo que ahora nos parecen artimañas para avalar las prácticas más siniestras de los conquistadores, fue también entonces un pensamiento innovador destinado a secularizar el ideal mundano de la reputación frente a los valedores de la sola contemplación religiosa ${ }^{38}$.

La posibilidad contraria a la batalla agresiva o defensiva que es la retirada (bien representada por don Diego) ${ }^{39}$, también es presentada en el segundo Quijote. Don Quijote recurre a esta estrategia cuando los «rebuznadores»

36. Sobre la aristocratización de los cargos oficiales: Domínguez Ortiz (1985: 183).

37. Si el vulgo no entendía qué ejemplaridad seguía Cervantes pintando a don Quijote como caballero temerario, el discreto sí: la ejemplaridad de un caballero ahora casi desconocido: don Manuel de León. No en balde el osado hidalgo era para el «autor» un «segundo y nuevo don Manuel de León, que fue gloria y honra de los españoles caballeros»: su precisión era un indicio para el buen entendedor. En efecto, don Manuel no solo fue uno de los pocos aventureros que el polémico Juan Ginés de Sepúlveda (2012: 178) recomendaba como modelo para los soldados de su tiempo, sino que también era ejemplo de soldados pasados a África para buscar el combate («don Manuel, en tiempos de nuestros padres o por mejor decir, en el nuestro, pasó a África a buscar ocasiones de alabanza y fama y puso carteles, como es costumbre, por toda Mauritania, desafiando a cualquiera valiente hombre que quisiese combatir con él, uno a uno; y como a esta fama y contienda viniesen cuasi de toda África muchos valentísimos hombres al lugar determinado para el combate, venció y mató siete de ellos, porque lo demás, viendo el manifiesto peligro y certidumbre de la muerte, no osaron combatir, y tornó en España con grandísima alabanza, trayendo en triunfo las cabezas de los siete, las cuales yo en Sevilla siendo muchacho vi». Además, fue un caballero conocido por haber recuperado el guante de una dama en una jaula de leones, Fradejas Lebrero (2008: 22-42). El mítico don Manuel se concebía entonces como un doble del Cid que, desarmado, hizo doblegar a un león. Emilio Martínez Mata, que opina que la referencia de Cide Hamete al Cid o a don Manuel Ponce de León es irónica (2015: 90), parece desconocer la valoración positiva que hace Cervantes de estos caballeros en $E l$ gallardo español para caracterizar a Saavedra como «coco de la morisma» y «Atlante de España» (v. 43). A este tipo de reflexiones sobre el pacifismo del autor, Insua Rodríguez pregunta «¿qué pinta el supuestamente 'erasmizante' Cervantes en Lepanto? y, sobre todo, ¿qué pinta además comportándose como se comportó nuestro autor en aquel "dichoso día", en aquella "felicísima jornada", en "la más memorable y alta ocasión que vieron los pasados siglos, ni esperan ver los venideros"?, ¿qué pinta, insistimos, "militando debajo de las vencedoras banderas del hijo [Juan de Austria] del rayo de la guerra, Carlo Quinto, de felice memoria"?» (2017: 21). A propósito de don Quijote, «caballero de los leones», es probable que el motivo del combate con el león también se relacione por isomorfismo mítico con las dos historias prototípicas de Hércules y Sansón, Darnis (2016a: 144-147), en particular frente al bachiller Sansón (Carrasco), «no muy grande de cuerpo», pero agudo representante del poder insidioso de los letrados en la Segunda parte.

38. La dimensión contemplativa de don Diego, posible recuerdo de las posiciones de Ginés de Sepúlveda, está subrayada no solo por su apellido «Miranda», sino también por su comportamiento durante el episodio («En todo este tiempo no había hablado palabra don Diego de Miranda, todo atento a mirar y a notar los hechos y palabras de don Quijote») y por la homología insinuada con el comportamiento del león: «Después de haber mirado a una y otra parte, como se ha dicho, volvió las espaldas y enseñó sus traseras partes a don Quijote, y con gran flema y remanso se volvió a echar en la jaula», Cervantes (1998: 766).

39. Para Ginés de Sepúlveda, un «valeroso soldado» «ha de venir al campo con tal ánimo que de ninguna cosa menos piense que de rendirse sino que venga determinado de vencer o morir» (2012: 189). 
arremeten contra él y Sancho (II, 27) ${ }^{40}$. Pero, precisamente en este caso, lo que se critica son, gracias al subtexto lucianesco, las guerras intestinas cuando un peligro mayor llama a las puertas de la península ${ }^{41}$. Ante los leones del Monarca, sin embargo, don Quijote no se arredró.

Desde el inicio de su nuevo libro, Cervantes esclarece una de las especificidades de la Segunda parte, un cambio respecto de la Primera. En el discurso de su héroe, antepone ahora la protección militar al resto de los ideales que antes valoraba don Quijote; en 1615, los «verdaderos caballeros» tienen a su cargo primero «la defensa de los reinos», y solamente luego «el amparo de las doncellas, el socorro de los huérfanos y pupilos» (II, 1: 633) ${ }^{42}$.

Sobre este trasfondo histórico-literario, Miranda resulta ser un oxímoron y un emblema incoherente, en particular porque su caballo parece desprovisto de cualquier valor militar: revestido con un gabán de función más decorativa que utilitaria ( $\mathrm{si}$ no es la de simbolizar por su color verde el concepto de viaje como recreo y mera caminata ${ }^{43}$, el caballero representa, según varios críticos, una «decadencia» dentro del estamento que ocupa ${ }^{44}$. Si retomamos las categorías de la época que se remiten a los tres ámbitos de la acción humana, y que son lo ético (la persona), lo económico (el hogar) y lo político (el cual abarca el espacio de las entidades nacionales o supranacionales), comprenderemos que el «discreto caballero» mutiló su amplia función social en pro de una responsabilidad centrada exclusivamente en los ámbitos éticos y económicos ${ }^{45}$. Es un personaje «moderno», sí; empero a estas alturas, ¿sigue siendo un «verdadero» caballero?

40. Sobre la cuestión de la retirada podemos acudir a las reflexiones de Layna Ranz (2005: 274278). Esencial es desde este punto de vista la evolución de don Quijote al final de la Segunda parte: Layna Ranz (2005: 274-278) y Darnis (2016a: 195-236).

41. «No huye el que se retira -respondió don Quijote-, porque has de saber, Sancho, que la valentía que no se funda sobre la base de la prudencia se llama temeridad, y las hazañas del temerario más se atribuyen a la buena fortuna que a su ánimo. Y así, yo confieso que me he retirado, pero no huido; y en esto he imitado a muchos valientes, que se han guardado para tiempos mejores, y desto están las historias llenas, las cuales, por no serte a ti de provecho ni a mí de gusto, no te las refiero ahora», Cervantes 1998 (II, 28: 863). En El gallardo español, la retirada es necesaria cuando lo pide un jefe militar y «donde está cierto el perderte» (v. 2863). A don Fernando Saavedra, que estaba disponiéndose a morir «al pie de» las murallas del presidio para protegerlo, Guzmán le pide que obedezca al gobernador retirándose). Este concepto de guerra «intestina» es tratado precisamente por Ginés de Sepúlveda en su Exhortación a Carlos V (2003: 344).

42. Recordemos las cinco razones que justifican la guerra: «Los varones prudentes, las repúblicas bien concertadas, por cuatro cosas han de tomar las armas y desenvainar las espadas, y poner a riesgo sus personas, vidas y haciendas: la primera, por defender la fe católica; la segunda, por defender su vida, que es de ley natural y divina; la tercera, en defensa de su honra, de su familia y hacienda; la cuarta, en servicio de su rey, en la guerra justa; y si le quisiéremos añadir la quinta, que se puede contar por segunda, es en defensa de su patria», Cervantes (1998, II, 27: 859-860).

43. Gingras (1985: 135-136).

44. Sobre la «decadencia» que representaría el caballero de Miranda coinciden tanto Navarro Ledesma (1960: 253, 276) como Márquez Villanueva (2011: 93-142).

45. Para Emilio Martínez Mata, Cervantes propone con el caballero de Miranda un modelo moderno de esa «nueva mentalidad enfocada a una virtud cívica» (2015: 99). 


\section{QUINTA OBSERVACIÓN: EL CREADOR ESTUDIADO Y LA LITERALIDAD}

Recurrir al pensamiento sepulvediano puede parecer excesivo cuando se estudia a un protagonista que la crítica canonizó como un idealista «moderno». Pero el Quijote es quizá menos sencillo y moderno de lo que parece a veces. Recordemos a Pierre Menard. Su segunda exégesis, la de la anacronía sistemática, amputa el texto de su entorno y de su autor. La primera, sin embargo, a la cual nos ajustaremos, supone «[s]er, de alguna manera, Cervantes y [luego] llegar al Quijote» olvidando por cierto toda la historia de la cuenca mediterránea desde 1616.

Retomando nuestro método de la lectura superficial, podemos fijar nuestra mirada ahora en otro detalle del episodio, acaso el más importante.

¿Con qué se cruzan precisamente Sancho, don Diego y don Alonso (don Quijote)? Escuchemos atentamente las palabras del leonero: «Lo que va en [el carro] son dos bravos leones enjaulados, que el general de Orán envía a la corte, presentados a Su Majestad; las banderas son del rey nuestro señor, en señal que aquí va cosa suya» (II, 17: 762). No debió de precisar Cervantes el origen de los leones, macho y hembra, sin razón. Los dos animales no vienen de cualquier lugar de la Monarquía hispánica: llegan de Orán. Dado el contexto del momento, huelga decir que este origen africano merece varias observaciones más, relacionadas todas con la microhistoria de don Miguel y la macrohistoria del Mediterráneo en la Modernidad temprana. Propondré primero los dos siguientes: Orán como liberación y el león como representación de la fuerza de la Monárquica hispánica en África.

\section{a) Orán como liberación}

Es sabido, en primer lugar, que la ciudad de Orán, conquistada en 150946, es a finales del XVI y principios del XVII el principal refugio terrestre para cualquier cautivo de Argel con proyecto de fuga. Fue así este destino el que eligió varias veces Cervantes cuando intentó escapar entre los años 1576 y 1578 al menos.

La ciudad albergaba un doble presidio junto con Mazalquivir, el puerto situado a poco menos de una legua. La plaza fuerte, para aquellos que sabían de cautiverio en Berbería, era, en efecto, todo un símbolo de libertad y de retorno «a casa». Es más: fugarse a Orán es casi un gesto de solidaridad en cuanto evitaría a los familiares el pago del rescate si el fugitivo llega a alcanzar la plaza ${ }^{47}$.

46. Los puertos de Argel y Trípoli fueron conquistados al año siguiente.

47. Alonso Acero (1997: 501-519). Se olvida a menudo que la frase más citada del Quijote sobre el ideal de libertad se corresponde con el ideal concreto de libertad para los cautivos antiguos, presentes y futuros de los baños africanos («La libertad, Sancho, es uno de los más preciosos dones que a los hombres dieron los cielos; con ella no pueden igualarse los tesoros que encierra la tierra ni el mar encubre; por la libertad, así como por la honra, se puede y debe aventurar la vida, y, por el contrario, el cautiverio es el mayor mal que puede venir a los hombres», Cervantes (1998, II, 58: 1094). 


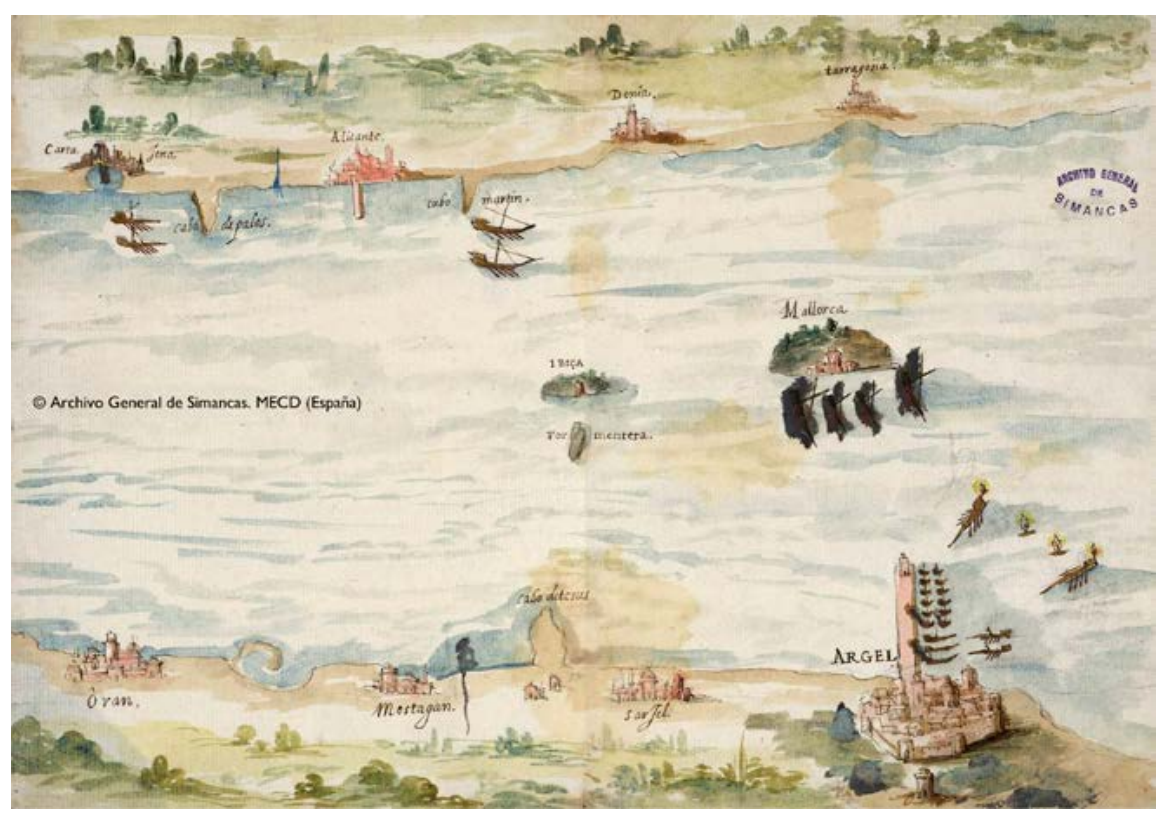

FIGURA 1. «Galeras en el Mediterráneo oriental para la lucha contra los corsarios de Argel», Aguada, 1621 (Archivo General de Simancas, colección de mapas, planos y dibujos, 67, 24).

Pero Orán se encuentra a unos $350 \mathrm{~km}$ de Argel. De los distintos riesgos que corre el fugado, el de los leones representa el más fantasmático del viaje. El cautivo temerario no solo puede sufrir las represalias de su amo si lo encuentra antes de llegar. También, aparte de la muerte por hambre, sed y desorientación, le han dicho que lo pueden devorar los leones salvajes de la zona $^{48}$. Para el lector discreto, los dos ejemplares enviados por el gobernador del presidio a $\mathrm{Su}$ Majestad constituyen así en el Quijote una representación inequívoca de los peligros africanos que imaginan y a veces padecen los cautivos prisioneros de Argel, y que si leemos con atención, se encuentran en el libro en varias secuencias cruciales: en la cueva de Merlín, el retablo de Melisendra o el caso barcelonés de don Gregorio ${ }^{49}$.

48. Sobre los leones del reino de Tremecén, véase Luis de Mármol Carvajal (1573: f. 172r y 223r) (para otras zonas del norte de África, véanse también los fol. 73r, 105r, 166v. En Sofroy -fol. $162-$, los leones tienen fama de ser medrosos y huir en caso de peligro). En El trato de Argel, Pedro Álvarez es protegido en su viaje a Orán por un «manso y fiero león» que «sin duda es divina cosa» (v. 2039). Más allá de las diferencias, un trabajo señala una correspondencia significativa: por el desenlace feliz tanto del episodio del segundo Quijote como de la obra del Trato de Argel, «Cervantès valide (en partie et sans doute de manière nostalgique) le choix de la témérité face aux dangers», Darnis (2016a: 150).

49. Darnis (2016a). Los intentos de Cervantes de escapar del baño de Argel son una clara prueba de su temeridad y quizá de la eficacia de este comportamiento «caballeresco», como él mismo afirma oblicuamente en el relato del cautivo: «Un soldado español, llamado tal de Saavedra, el cual, 


\section{b) África enjaulada}

Escuchemos las palabras del mensajero que aclaran el sentido literal de la secuencia. Los guardianes del presidio han querido enviar al Rey una imagen viva de la fuerza militar de la Monarquía hispánica en África: según dice el leonero, «no han pasado mayores [leones], ni tan grandes, de África a España jamás $\rangle^{50}$. Que la prisión de los leones represente por definición la capacidad real de la fuerza y coerción (militar) sobre los musulmanes africanos, no debe sorprender. En el sistema militar defensivo contra los ataques de los otomanos $\mathrm{y}$ de los corsarios berberiscos, Orán ${ }^{51}$ formaba el vértice inferior de un triángulo que, desde el norte de África, intentaba proteger por un lado las costas de la península ibérica y por otro los territorios del reino de Nápoles ${ }^{52}$. Además, desde 1609 y la Tregua de los Doce Años con Holanda (o con las Provincias Unidas), se observa un tímido «giro al sur» en la política internacional de España ${ }^{53}$.

con haber hecho cosas que quedarán en la memoria de aquellas gentes por muchos años, y todas por alcanzar libertad, jamás le dio palo, ni se lo mandó dar, ni le dijo mala palabra; y, por la menor cosa de muchas que hizo, temíamos todos que había de ser empalado, y así lo temió él más de una vez; y si no fuera porque el tiempo no da lugar, yo dijera ahora algo de lo que este soldado hizo, que fuera parte para entreteneros y admiraros harto mejor que con el cuento de mi historia», $c f$. Cervantes (1998, I, 40: 463). Así, denunciando su sola responsabilidad en 1579 para evitar que sus compañeros de huida fueran martirizados, Cervantes tendría la impresión de haberles salvado el pellejo.

50. «-El carro es mío; lo que va en él son dos bravos leones enjaulados [...].

-Y ¿son grandes los leones? -preguntó don Quijote.

-Tan grandes -respondió el hombre que iba a la puerta del carro-, que no han pasado mayores, ni tan grandes, de África a España jamás; y yo soy el leonero, y he pasado otros, pero como éstos, ninguno», Cervantes (1998, II, 17: 762).

51. Ahmed Abi-Ayad subraya la relevancia del presidio de Orán en las obras de Miguel de Cervantes (1998 y 2004).

52. Martín Corrales (2008: 1867): «En los enfrentamientos marítimos entre españoles y musulmanes, las plazas norteafricanas en poder de los primeros jugaron un papel realmente importante. Cumplieron una doble función: hostigar con sus embarcaciones armadas a los corsarios y a la navegación norteafricana y, con su ocupación de los mejores puertos naturales del litoral norte, impedir la emergencia y consolidación de importantes bases corsarias norteafricanas. Sin duda alguna, tuvieron éxito en la franja del litoral comprendida entre Ceuta y Orán ya que, salvo el caso de Tetuán, la amenaza corsaria para el litoral y naves españolas provino fundamentalmente de los puertos al este de Orán y al sur de Ceuta. Claro que la ocupación hispana de los mejores, o casi los únicos puertos naturales de la zona, impidió el desarrollo de una economía marítima y, por lo tanto, el desarrollo económico de la zona. Esto es importante ya que hablamos de una región pobre». También Alonso Acero (2012: 70).

En realidad, desde 1574, «tan sólo unos días después de la capitulación de Túnez, el Consejo de Estado discute sobre la permanencia de Orán y Mazalquivir dentro de la Monarquía Hispánica», Alonso Acero (1997: 13).

53. Alonso Acero (1997: 27). Sobre la lucha contra el corso musulmán: «También serán decisivas las consecuencias derivadas del aumento de individuos dedicados a estas actividades a raíz de la expulsión de los moriscos entre 1609 y 1614. Un número importante de estos moriscos se trasladará al norte de África, y si bien una parte de ellos encauza su existencia en el continente vecino a través de labores agrícolas y artesanas -especialmente en Túnez-, otros muchos se convierten en corsarios al servicio de las flotas turcas y berberiscas, provocando un incremento sustancial de la cantidad de asaltos a barcos cristianos que navegan por las aguas del Mediterráneo occidental y Atlántico norteafricano. Esta introducción de los moriscos en las actividades corsarias viene explicada, en primer 
¿Qué representa entonces literalmente don Quijote frente a estos leones? A la vista de la documentación histórica y literaria, parece que el modelo bélico que encarna el hidalgo se corresponde con el famoso «socorro» que realizaron en 1563 don Francisco de Mendoza, capitán general de las galeras de España, y el marqués de Santa Cruz junto con «muchos caballeros de Castilla, Aragón, Valencia y Cataluña» ${ }^{54}$. Todos, desde varios puntos de la Monarquía, acudieron a Orán y Mazalquivir para deshacer el asedio organizado por el rey de Argel Hassán Bajá, consiguiendo así «liberar» al presidio. Es precisamente este combate el telón de fondo de la comedia El gallardo español, publicada en 1615, el mismo año de la publicación de la Segunda parte $^{55}$.

No me parece, por lo tanto, que se pueda afirmar que, cuando el león quijotesco «se volvió a echar en la jaula», Cervantes diseñe una forma de «desprecio» hacia la temeridad representada por el ingenioso hidalgo ${ }^{56}$.

Si se considera el león un símbolo de resistencia «mora», podemos decir que Cervantes publica en 1615 dos vertientes de una misma acción defensiva pues ni el caballero Saavedra ni don Quijote dudan en afrontar al «león» de África. Quizá aparezca más claramente la lógica militar y patriótica del hidalgo si recordamos las palabras del general de Orán en la comedia:

lugar, por su deseo de venganza frente a los autores de su expulsión, pero también, en determinados casos, hay una necesidad de demostrar a sus hermanos de religión hasta dónde son capaces de llegar para hacerles ver que su confesión religiosa nunca ha dejado de ser la musulmana. El buen conocimiento de las costas españolas de gran parte de estos moriscos expulsados hará que sean aceptados como corsarios que dirigen las expediciones de ataque no sólo contra los barcos cristianos, sino contra las propias costas peninsulares, incrementándose de esta forma la amenaza contra las poblaciones asentadas en los territorios ribereños», Alonso Acero (1997: 30).

54. Mármol Carvajal (1573: f. 206v).

55. Sobre la fuerza de disuasión de la armada de don Francisco de Mendoza y la huida precipitada de los autores del cerco de Orán de 1563, Morales señaló que «en viendo las galeras hicieron gran diligencia en retirarse, dejándose el artillería, que eran unas piezas gruesas y otras pequeñas, y gran cantidad de municiones y bastimentos y pertrechos de guerra» (citado por Gómez Canseco en Cervantes 2015, II: 317). El estereotipo de la cobardía musulmana delante del arrojo español se encuentra formulado en varios autores como Ginés de Sepúlveda (2003: 342): «Esa masa de enemigos» es «un gran rebaño de oveja» o el autor del Viaje de Turquía «le conosçen [al Turco] ser fortíssimo contra quien huye y fugaçíssimo contra quien le muestra resistençia» (2010: 94). Nótese que en $E l$ trato de Argel, Sayavedra explica que la «gente [berberica y turca] es mucha, mas su fuerza es poca» (Cervantes 2015: 927, v. 429). Coinciden Cervantes y Cabrera de Córdoba para decir que eran «medrosos» los turcos en el puerto griego de Navarino (hoy Pilos), al encontrarse dispuestos a huir «todos los leventes y jenízaros que en ella venían tuvieron por cierto que les habían de embestir dentro del mesmo puerto, y tenían a punto su ropa y pasamaques, que son sus zapatos, para huirse luego por tierra, sin esperar ser combatidos: tanto era el miedo que habían cobrado a nuestra armada», Cervantes 1998 (I, 39: 455); véase Cabrera de Córdoba (1998: 634). Ambos se quejan también de que no se haya destruido la armada de la Gran Puerta: para Cabrera de Córdoba, «levantó don Juan el cerco [...] por falta de comida y por ser fuerza invernar en Poniente» (1998: 632); para el «cautivo» de Cervantes, muy ducho en la crítica oblicua parece evidente «la ocasión que allí se perdió de no coger en el puerto toda el armada turquesca [...]. Pero el cielo lo ordenó de otra manera, no por culpa ni descuido del general que a los nuestros regía, sino por los pecados de la cristiandad, y porque quiere y permite Dios que tengamos siempre verdugos que nos castiguen», Cervantes 1998 (I, 39: 455).

56. Es el punto de vista interesante, aunque para mí erróneo, de Emilio Martínez Mata (2015: 90). 
Señor don Martín, conviene que vuesa merced acuda a Mazalquivir, que tiene necesidad de la ayuda que vuestro esfuerzo contiene; que allí acudirá primero el enemigo ligero.

Mas, que venzáis no lo dudo; que el cobarde está desnudo, aunque se vista de acero.

En su muchedumbre estriba aquesta mora canalla, que así se nos muestra esquiva; mas, cuando defensa halla, se humilla, prostra y derriba.

Sus gustos, sus algazaras, si bien en ello reparas, son el canto del medroso; calla el león animoso entre balas y jaras (vv. 536-551, la cursiva es mía).

Para Cervantes, tenía mucho sentido que el caballero de Santiago ${ }^{57}$ y gobernador del presidio se dirija en la comedia a su hermano don Martín para proseguir la ocupación del territorio africano ${ }^{58}$. Como recuerda Gómez Canseco, Cervantes «le dirigió unas cartas en 1578 para organizar su tercer intento de fuga y coincidió personalmente con él más tarde, en $1581 »$, durante su «misión secreta» en Orán ${ }^{59} \ldots$

57. Sobre el punto de vista de don Quijote sobre la orden de Santiago, que sufrió con la muerte de don Juan de Mendoza un duro golpe en la Herradura, es de especial importancia el capítulo 58: «Por buen agüero he tenido, hermanos, haber visto lo que he visto, porque estos santos y caballeros profesaron lo que yo profeso, que es el ejercicio de las armas; sino que la diferencia que hay entre mí y ellos es que ellos fueron santos y pelearon a lo divino, y yo soy pecador y peleo a lo humano. Ellos conquistaron el cielo a fuerza de brazos, porque el cielo padece fuerza, y yo hasta agora no sé lo que conquisto a fuerza de mis trabajos; pero si mi Dulcinea del Toboso saliese de los que padece, mejorándose mi ventura y adobándoseme el juicio, podría ser que encaminase mis pasos por mejor camino del que llevo», Cervantes (1998, II, 58: 1097). Véase Darnis (2016a: 155-156).

Es interesante también que el nombre del caballero de Miranda recuerde la vida de fray Diego de Alcalá, a quien, señala Redondo, «se le atribuyen numerosos milagros» (1998: 284). Así como Sansón Carrasco puede representar una degradación del Sansón mítico, Miranda podría plasmar una degradación y una inversión de otro «san Diego»: Santiago Matamoros, el patrón de la más famosa de las órdenes militares, citado en el cap. 58 (1998: 286-287). Me parece importante señalar que los debates sobre las órdenes militares giraban en torno a la necesidad o no de realizar lo que Fernando el Católico propuso en el Capítulo General de la Orden de 1509: la fundación siempre aplazada en Orán de un convento, «a donde sin ninguna excusa, debían acudir los caballeros para recibir su hábito», Jiménez Moreno (2011: 307).

58. Sobre la familia de los Córdoba y su presencia en las fronteras mediterráneas: Liang (2011).

59. Tenían algo en común el futuro gobernador don Martín de Córdoba y Cervantes: ambos han sido cautivos en Argel (según Chaulet y Ortega (2013), este duró para el caballero de Santiago unos tres años). 
Este primer nivel de lectura, que se ajusta con el mensaje que el leonero envía al rey ${ }^{60}$ y asocia al león con el peligro africano, no cuadra sin embargo con el resto de los componentes que estructuran la secuencia. Que Cervantes presente a sus lectores una pareja de leones, por ejemplo, aleja sin duda la comprensión de la secuencia de la literalidad anterior.

SEXTA OBSERVACIÓN: EL CREADOR ESTUDIADO Y EL «ALMA»DE LA FÁBULA

Para la crítica ultra-literarista, los investigadores deberían abandonar el concepto áureo de «poesía» para ajustarse al contemporáneo de «literatura», aunque este sea anacrónico. Deberíamos hacer caso omiso de las nociones antiguas, por ser poco compatibles con el concepto actual de «literatura». Así, unos prefieren olvidar que, para A. López Pinciano, por lo que se refiere a las obras de arte, le conviene al lector leer más allá de las apariencias y percibir la dimensión alegórica de la obra, que es «el tuétano o meollo de la imitación o fábula». Para aquella rama de la crítica, es incomprensible que Pinciano afirme que «para el enseñar basta que [la obra] tenga alegoría» ${ }^{61}$. Para un autor tan «moderno» como Cervantes, suena también rancia la idea de Luis Alfonso de Carvallo de que son puras «mentiras» las «ficciones» que no tengan sentido alegórico ${ }^{62}$.

El problema de este planteamiento metodológico es que, como precisa el prólogo del primer Quijote, en vez de excluir la lectura profunda, la escritura mimética la requiere. El «amigo» recomienda al «autor» que pinte su historia «dando a entender [sus] conceptos», a imagen precisamente de lo que preconizaba Carvallo: los poetas componen historias con «ciertas señales con que se significan las verdades». Si el vulgo no percibe la alegoría, «bastarle ha saber que no lo sabe y entender que alguna cosa significa la ficción que él no alcanza» ${ }^{63}$. En efecto, en el Quijote, el «principal intento» de Cervantes debió de ser similar al que introdujo en la comedia oranesa:

ha sido mezclar verdades

con fabulosos intentos (vv. 333-334).

60. Mar Martínez Góngora percibe en «la magnificencia del obsequio realizado por el gobernador a Felipe II [...] como una prolepsis del episodio del palacio de los Duques, en el que Cervantes critica la ociosidad y el abuso de poder de los aristócratas de su tiempo» (2013: 374-375).

61. López Pinciano (1998: 169).

62. Carvallo (1997: 115).

63. Carvallo (1997: 117-115). 


\section{a) Los leones y la pareja real}

Así como Cervantes cuestiona el heroísmo del caballero del verde gabán, también hace lo propio con el brío del león. Las primeras manifestaciones del macho van a responder a lo que se espera de un emblema tradicional de la realeza. El "León del Imperio", como dice H. Percas de Ponseti64, parece ser un paradigma del arte de la disuasión: "Sacó la cabeza fuera de la jaula y miró a todas partes con los ojos hechos brasas, vista y ademán para poner espanto a la misma temeridad ${ }^{65}$. ¿No se parece, pues, el animal a don Fernando, el héroe del presidio oranés de El gallardo español, quien se presenta «atrevido» como «un león» ${ }^{66}$ ? De la misma manera, no es imposible que el dúo de leones (macho y hembra) se haya pensado para que pueda funcionar como una alusión (o significatio) a la pareja real ${ }^{67}$.

Pero lo que ocurre en el pasaje es en realidad inquietante si los lectores asocian los dos "leoncitos" no con el simbolismo abstracto del león, sino con el de su lugar de origen: Orán y la situación de los representantes de la monarquía, a saber, los soldados del presidio... El hecho es que el fiero león «con gran flema y remanso se volvió a echar en la jaula» (II, 17: 766). ¿Por qué, ante un asedio inminente, el máximo emblema de la Monarquía hispánica en Berbería vuelve «las espaldas» y enseña «sus traseras partes» ${ }^{68}$ ? Para cualquier lector familiarizado con la situación del presidio de Orán ${ }^{69}$, las indirectas del ex-soldado Cervantes eran sin duda transparentes: el rey de los animales es, de verdad, poco impresionante.

¿No pensaban algunos que el fortalecimiento de la presencia española en el norte de África atajaría de una vez el comercio de cautivos que vaciaba las arcas reales luchando contra el corso y subvencionando las misiones de rescate de las órdenes religiosas ${ }^{70}$ ? Lo que sí es fundamental saber es que precisamente, justo después del regreso de don Miguel a la península, la Monarquía lo envía a Orán en 1581 para realizar una misión secreta sobre la que tenemos escasa información. Es probable que el veterano de Lepanto haya formado parte de los observadores que iban al presidio norteafricano para confirmar o

64. Percas de Ponseti (1975: 329).

65. Recordemos que los dos leones son, dice el «autor», «los dos más fieros [...] que jamás criaron las africanas selvas» (II, 17: 766).

66. Cervantes (2015: 53, v. 907).

67. Reichenberger (2006: 34) ve en el león un símbolo de la monarquía castellana.

68. Hay que recordar que la primera reacción del león ya daba indicios de su flema: «Lo primero que hizo fue revolverse en la jaula, donde venía echado, y tender la garra, y desperezarse todo; abrió luego la boca y bostezó muy despacio, y, con casi dos palmos de lengua que sacó fuera, se despolvoreó los ojos y se lavó el rostro», Cervantes (1998, II, 17: 766).

69. El presidio tenía una reputación tan mala que para realizar las levas se recurría a la trampa de explicar a los futuros soldados que iban a Italia, Alonso Acero (1997: 235-236).

70. Véanse las puntualizaciones de Malcolm sobre las peticiones de Felipe II en las negociaciones para formalizar la Santa Liga (2016: 204-206). La descripción general de África de Mármol Carvajal supone un ejemplo de cómo los «africanistas» españoles intentaban convencer al Consejo de Guerra para que aceptara mandar más «gente, municiones y bastimentos» con el objeto de controlar toda la zona entre Orán y Argel (1573: fols. 196r-197r). 
refutar la veracidad de los datos catastróficos que recibía la Corona a finales del siglo XVI ${ }^{71}$. Según se puede rastrear en los avisos mandados a la Cancillería, se hace hincapié tanto en la debilidad de la infraestructura militar como en la situación de los soldados, sobre todo a partir de $1610^{72}$. En estos años, la vida de la gente de guerra se consolida, dice Beatriz Alonso, «como una lucha contra el hambre y la desnudez» ${ }^{73}$ abocando a muchos soldados a la deserción o a la apostasía ${ }^{74}$. ¿No dice el carretero que «ahora van hambrientos [los animales] porque no han comido hoy»? No explica que «es menester llegar presto» para que se les dé rápidamente «de comer» (II, 37: 762)?

La miseria era la suerte de la mayor parte de los puestos de avanzada, de los presidios situados en regiones fronterizas; pero, aunque ahora podemos cuestionar la legitimidad y la eficiencia de la ocupación africana ${ }^{75}$, bien podemos imaginar que, para un antiguo cautivo de su Majestad y excombatiente de los Tercios Miguel de Cervantes, el balance geomilitar de Orán era insoportable. Tan insoportable que alguien se quejaría luego contra «tan penosa esclavitud como la de Orán $»^{76}$. Se induce así del león manso que los militares del presidio se encuentran en una situación de peligro que su propia ubicación geográfica de encierro no hace más que reforzar ${ }^{77}$. Así, cuando Sancho pre-

71. Otra hipótesis sobre la misión de Cervantes correspondería a la función de inteligencia en la red mediterránea de puestos de avanzada en un contexto de preparación de la jornada de Argel. Orán, por ser zona de frontera y tener contactos múltiples con los «moros de paz» (entre ellos estaban los llamados «mogataces» o musulmanes que servían como espías o auxiliares), defendía los intereses de la Monarquía mediante una labor de información para alertar de ataques corsarios e impedir las «bajadas del Turco», Alonso Acero (2012: 85-86). Sobre los avisos de Argel mandados desde Orán: Alonso Acero (1997: 77-78).

72. Léase, por ejemplo, el aviso de Diego Galán estudiado por Bunes Ibarra (2011: 323-368) y Sáez (2018). Para una visión general, que destaca tanto las penalidades de abastecimiento como el problema de las pagas insuficientes y a menudo atrasadas: García-Arenal y Bunes Ibarra (1992: 267274). Sobre los problemas específicos de los militares: Alonso Acero (1997: 234-318).

73. Alonso Acero (1997: 292). Recuérdese al personaje del militar pordiosero Buitrago, que denuncia el hambre de la milicia en Orán, El gallardo español, en Cervantes (2015: 67, 71 y 126).

74. Véase, por ejemplo, la carta en este sentido del marqués de Ardales al Consejo de Guerra, Alonso Acero (1997: 314). Cervantes evoca, por lo demás, este problema en El gallardo español, en Cervantes (2015: 130).

75. García-Arenal y Bunes Ibarra (1992: 267-274) insisten en que el aislamiento militar y confesional de los militares creó un ciclo económico nefasto para la región, que afectaba tanto a los habitantes de la zona como a los que vivían dentro del presidio. Cabe decir también que la opción militar no siempre resulta ser quizás la más eficaz: cuando «Francia, Inglaterra y Holanda se plantean luchar contra el corso utilizando medidas diplomáticas, tanto en la propia Argel como en Estambul, recurriendo sólo a la fuerza cuando se demuestra que esta vía no es válida, la monarquía de Felipe III insiste, desde los primeros años de su gobierno, en la necesidad de realizar acciones militares directas contra las urbes que se dedican a esta actividad», Bunes Ibarra (2006: 95).

76. Duque de Maqueda, citado por Alonso Acero (1997: 314).

77. La imagen del «bravo» león encarcelado como antes don Quijote (I: 46-48) en una jaula quizá apunte al aislamiento de las fuerzas militares recluidas en el presidio. La debilidad del presidio era grave pues, en palabras de Beatriz Alonso Acero, tenía una notable relevancia para «el avituallamiento de Nápoles y Sicilia gracias al grano conseguido a bajo precio a través de los tratos de los gobernadores de este presidio con las tribus musulmanas del entorno» (2012: 70). Mazalquivir, que servía de puerto de Orán, «se alzaba en su totalidad sobre una peña viva, rodeada de una sierra de gran elevación, y tenía a su favor el albergar el mejor puerto de toda la Berbería, el Portus Magnus romano, del que Juan 
gunta al leonero «¿Qué se han hecho los leones? ¿Son muertos, o vivos?»y cuando caemos en la cuenta de que «el león, acobardado, no quiso ni osó salir de la jaula, puesto que había tenido un buen espacio abierta la puerta de la jaula» (II, 17: 767-768), los lectores avezados podían comprobar indirectamente cuál era la situación del presidio hispánico. En la batalla frustrada de don Quijote contra el león, no es imposible que Cervantes haya querido dirigir una velada lección de fortaleza monárquica $\mathrm{y}$, más seriamente, un arbitrio a los altos cargos de gobierno («a la corte», esto es, a los caballeros «cortesanos») para que se reajustara el poder hispánico en Orán. ¿No se nos presenta a don Quijote, al fin y al cabo, con su título de caballero «de los leones», como un rey en potencia ${ }^{78}$ ?

\section{b) La política de la Monarquía en el Mediterráneo}

El segundo comentario que quizá merezca el simbolismo de esta secuencia tiene que ver a lo mejor con la política internacional de la Monarquía hispánica. La voluntad belicosa del hidalgo puede encerrar la fuerza de un mensaje menipeo. Cervantes busca tal vez transmitir el deseo de un reajuste de la potencia hispánica en el Mediterráneo.

La secuencia posterior de destrucción del ejército moro, cuando este intenta dar alcance a la fugada Melisendra y a su indolente salvador Gaiferos, ¿no propone un sentido similar? ¿No sugiere Cervantes, haciendo que su hidalgo mate en el retablo incluso al emperador cristiano Carlomagno, que él no está conforme con la falta de ímpetu de la política mediterránea de Felipe III $^{79}$ ? ¿No muestra aquí el personaje colérico de don Quijote la importancia de la fuerza para liberar a los prisioneros cristianos en Berbería? A la inversa, la actitud pasiva del animal de Orán resulta sorprendente: el león, se nos dice, «tiene abierta la puerta: en su mano está salir, o no salir; pero, pues no ha salido hasta ahora, no saldrá en todo el día». Para un animal «bravo» y «fiero» que simboliza la fuerza monárquica, el atributo de la flema (temperamento opuesto a la cólera quijotesca) debió de dar mucho que pensar a los lectores discretos. La justificación del leonero es reveladora desde esta perspectiva: «Ningún bravo peleante, según a mí se me alcanza, está obligado a más que

León Africano refería que no había otro igual en todo el mundo hasta entonces conocido, pues era capaz de albergar cientos de navíos y galeras al abrigo de cualquier tempestad» (2012: 71).

78. II, 17: 768: «¿Qué te parece desto, Sancho? -dijo don Quijote-. ¿Hay encantos que valgan contra la verdadera valentía? Bien podrán los encantadores quitarme la ventura, pero el esfuerzo y el ánimo, será imposible [...]. Pues, si acaso Su Majestad preguntare quién la hizo, diréisle que el Caballero de los Leones, que de aquí adelante quiero que en éste se trueque, cambie, vuelva y mude el que hasta aquí he tenido del Caballero de la Triste Figura; y en esto sigo la antigua usanza de los andantes caballeros, que se mudaban los nombres cuando querían, o cuando les venía a cuento».

79. Recuérdense las palabras del duque de Maqueda, donde se culpaba al propio rey de la esclavitud de Orán: «Lastímame mucho que el olvido con que VM. trata estas plagas obligue a que los soldados dellas vayan a renegar de Dios y a negar a VM.», Alonso Acero (1997: 316). Sobre la crítica del «manso» Felipe II frente a su padre «el rayo de la guerra» y su militar hermanastro: Insua Rodríguez (2017: 46-55). 
a desafiar a su enemigo y esperarle en campaña; y si el contrario no acude, en él se queda la infamia, y el esperante gana la corona del vencimiento ${ }^{80}$.

Las coordenadas del Quijote al respecto apuntan a que Cervantes tenía una visión muy conflictiva (¿traumática ${ }^{81}$ ?) del mundo meridional y oriental. A lo largo de la Segunda parte, son reveladores de una preocupación mediterránea los debates preliminares, la cueva de Merlín, la historia de Melisendra y por último la de don Gregorio. Es difícil decir si, en su sátira menipeana ${ }^{82}$, Cervantes (como antes de él Alfonso de Valdés) intenta combatir el pacifismo que en Europa ha encontrado en Tomás Moro a uno de sus mayores defensores. Lo que sí parece evidente es la opción cervantina de un proyecto opuesto a la política de «ocupación restringida» del Mediterráneo que Felipe III heredó de su padre ${ }^{83}$. En efecto, más que la cobardía, el blanco de los dardos de Cervantes es la mansedumbre, que es atributo tanto del león como, de manera duplicada, de don Diego con su metonímico «perdigón manso» ${ }^{84}$. Ambivalente y cómica, la intentio auctoris se ceba en la tranquilidad satisfecha que aparece desde el primer capítulo cuando don Quijote ha dejado entender que el rey es menos cauto de lo que se piensa por la vulnerabilidad de los tres flancos orientales de la Monarquía: Nápoles, Sicilia y, por supuesto, la isla de Malta (II, 1: 627), situada entre la cristiana Siracusa (norte) y las musulmanas Túnez (oeste), Pilos (este) y Trípoli (Sur) ${ }^{85}$. Descubriendo al

80. Sobre el léxico del pasaje cervantino que asocia al león metafóricamente con un jefe militar, Percas de Ponseti (1975: 327). Ya en la Primera parte, se culpaba al rey (en este caso Felipe II) de haber desaprovechado la victoria de Lepanto para debilitar la influencia de los otomanos en el Mediterráneo occidental: «Vi y noté la ocasión que allí se perdió de no coger en el puerto toda el armada turquesca [...]. Pero el cielo lo ordenó de otra manera, no por culpa ni descuido del general que a los nuestros regía, sino por los pecados de la cristiandad, y porque quiere y permite Dios que tengamos siempre verdugos que nos castiguen» (I, 39: 455). Si Cervantes exculpa al general de la flota, no así a la política monárquica, a la que bien puede hacer referencia los imprecisos «pecados de la Cristiandad». Para un enfoque histórico global: Malcolm (2016). Sobre la paz con el Turco: Rodríguez Salgado (2004).

81. Garcés (2005).

82. Se emplea aquí el neologismo menipeano para no incurrir en la exageración que llevaría a afirmar que el Quijote es una sátira menipea. Pertenece a esta vena literaria sin definirse en puridad como tal.

83. Para Martínez Torres, los «Austrias [...] al contrario de lo que clamaban los miembros más belicosos de los Consejos de Estado, Guerra e Italia, no mantuvieron una política clara, eficaz y constante contra las ciudades corsarias del norte de África, capaz de cortocircuitar la hemorragia de soldados civiles capturados por los marinos musulmanes, sino que optaron, con la ayuda de la Iglesia, por recuperar la mayor suma posible de cautivos» (2004: 85). Sobre la crítica cervantina de los letrados en el gobierno de la monarquía hispánica: Moner (1986: 71-138), Layna Ranz (2005) y Darnis (2015a: 274-310 y 2016a).

84. Para Percas de Ponseti (1975: 337-338) y Martínez Mata (2015: 81), la caza con engaño de don Diego se opone a la caza con galgo de don Quijote.

85. El recurso a la retórica oblicua de la significatio es revelador de la dimensión polémica del arbitrio quijotesco: «Su Majestad ha hecho como prudentísimo guerrero en proveer sus estados con tiempo, porque no le halle desapercebido el enemigo; pero si se tomara mi consejo, aconsejárale yo que usara de una prevención, de la cual Su Majestad la hora de agora debe estar muy ajeno de pensar en ella» (II, 1: 627). 
«discreto» don Diego revestido de un traje que lo equipara con un león ${ }^{86}$, casi estamos viendo la política del «prudente» Felipe II, aquella que Cervantes censuraba sotto voce en el famoso poema escrito después del descalabro de la «invencible» Armada:

¡Ea pues, oh, Felipe, señor nuestro, [...]

vuele en suceso más felice y diestro este designio que fabrica el mundo, que piensa manso y sin coraje verte como si no bastasen a moverte [...] tus mares llenos de piratas fieros, por ello tus armadas encogidas, y en ellos mil haciendas y mil vidas sujetos a mil bárbaros aceros [...] (vv. 52-66) ${ }^{87}$.

En este poema manuscrito que tardará siglos en publicarse, Cervantes abogaba por una milicia temeraria y «hacer que se intente aun lo imposible» (v. 68):

en la justa ocasión y en la porfía

encierra la victoria su alegría (vv. 141-142) ${ }^{88}$.

La proximidad con las ciudades aliadas de Constantinopla hacía de estos puestos de avanzada hispánicos unas zonas vulnerables, tal y como experimentaban a menudo sus habitantes, sus marineros y, desde luego, sus soldados. Como bien sabe Cervantes, hasta en las proximidades de Barcelona podían esconderse corsarios berberiscos... La idea de inmovilismo debió de parecerle una «sinrazón» al autor de Don Quijote, cuando miles de cautivos seguían detenidos en las ciudades de piratas del norte de África.

\section{c) El proyecto de reforma militar}

De ahí que, en el indicio de la mansedumbre y del inmovilismo carcelario del león africano ${ }^{89}$, esté en juego algo más que la debilidad de algún presidio o la crítica de la política de pax. El episodio merece, pues, un último comentario. El seudoleón «bravo» no es el blanco principal de Cervantes: lo es sobre todo la otra impostura, la del «seudocaballero» ${ }^{90}$, la de aquel que gusta

86. Igualmente, conviene señalar con Clemencín que el color «leonado» del terciopelo del gabán y de la montera, al ser rojizo la piel de un león, emparenta a don Diego con el león enjaulado, Cervantes (1835: 273).

87. Cervantes (2015: 185).

88. Cervantes (2015: 185-188). Insua Rodríguez cita también El trato de Argel: «Despierte en tu real pecho coraje / la desvergüenza con que una bicoca / aspira de contino a hacerte ultraje», Cervantes (2015: 926, vv. 426-428).

89. El leonero, en cuanto carcelero, funciona como alegoría del General del presidio, que se llamaba también alcaide, Darnis (2016a: 151).

90. Sobre el inmerecido «don» y título de «caballero» de Diego de Miranda, es muy interesante el artículo de Baras (2010). 
de vestirse con vistosos colores verdes para pasearse sin alejarse demasiado de su amena casa. ¿No pertenece don Diego acaso de esa república donde «agora triunfa ya la pereza de la diligencia» (II, 1: 634)? ¿No es de aquellos linajes por cuya cobardía algunos reinos, por mucho que «comenzaron grandes», «acabaron en punta»? (II, 6: 675).

Desde finales del siglo XVI, y dentro de la polémica sobre la milicia en zonas orientales, otra controversia agitaba a los arbitristas hispánicos. En unos términos homólogos a los que hemos escuchado durante el primer capítulo en boca de don Quijote, varios arbitristas abogaban por un retorno a la vocación fundadora de las Órdenes Militares y, de manera general, de la aristocracia. Se trataba para estos militaristas de movilizar a los caballeros de Santiago, Calatrava y Alcántara con el fin de que justificaran sus privilegios y, de forma concreta y activa, defendieran las fronteras de la Monarquía. En particular después de la expulsión de los moriscos, distintos memoriales querían que se destinara a los «caballeros» a la defensa de los reinos contra «el Turco»siguiendo el ejemplo de la muy rigurosa orden de san Juan (la de Malta). Dentro de estos proyectos, Orán ocupaba un lugar destacado, pues los arbitristas pensaban devolverle su función de plaza fuerte y de escuela de formación militar ${ }^{91}$.

A estas alturas, era esencial para Cervantes no la puesta en escena de la cobardía monárquica ni la de la temeridad quijotesca por separado, sino su hábil conjunción narrativa. Merced a esta asociación y contraste textual, el afán agresivo de don Quijote no aparecía ya tal vez como un abuso arbitrario. La petición de «caballerosidad» bélica de don Quijote se ha dotado de un valor importante porque, precisamente, podía compensar lo que, en la ficción, representaba la debilidad de la milicia monárquica y, de manera amenazadora para ella, hacía de Orán la posible víctima de una próxima reconquista turco-

91. Léase, por ejemplo, el arbitrio Discurso sobre el exercicio militar de las órdenes militares para defensa de las costas de África (ca. 1610): «Mandamos que luego se haga un convento de la santa orden y cavallería en la çiudad de Orán [...]. Las utilidades y provechos que se siguirían de ponerlo por obra son muchas y muy evidentes. [...] tendrá la nobleza de España en qué exerçitarse y no estar tan oçiosa como la vemos en las calles y plazas públicas, inquietar las donçellas honrradas y infamando sin culpa muchas mujeres prinçipales y ocasionando muchos casamientos que traen infamia, no solo a ellos, pero a todo / su linaje, y si huviese este santo exerçiçio no habría grande, ni título, ni cavallero prinçipal que no quisiese embiar a tan santa escuela sus hijos segundos y terçeros, y aun por ventura los primeros, de que resultaría que la miliçia andaría entre gente noble y no entre gente desgarrada como agora la vemos, y esto prinçipalmente es más neçesario en estos tiempos que en otros, que con las payes que ay en los estados de Flandes, del todo pareze estar yerrada la puerta para el exerçiçio militar de la gente noble. [...] que por este camino se enseñarían todos los nobles a ser muy buenos soldados, y saldrían capitanes insignes para las ocasiones en que fuesen neçesarios, y no abría la penuria que agora ay dellos, pues en ofreciéndose la ocasión no pareçe que ai quien volver los ojos, y esto se causa de no aver exerçiçios militares [...] La $6 .^{\text {a }}$ [razón] y no menos principal que resultaría desto es una gran defensa que tendrán las costas de España, pudiendo vivir con una gran seguridad, sin temer ocasiones repentinas ni traiçiones de enemigos, pues los enemigos no se atreverían a ponerse con tan manifiesto peligro a invadir las costas», citado por Fernández Izquierdo (1992: 233-245). Sobre el papel que varios arbitristas quieren dar juntamente a Orán y a las órdenes de caballería entre los años 1596-1612, es fundamental la tesis de Jiménez Moreno (2011: 307-330). 
berberisca, a imagen de las ya perdidas Trípoli (1551), la Goleta y Túnez (1574) algunos años antes ${ }^{92}$.

Dentro del propósito desmitificador de la Segunda parte sobre la falsa nobleza, se ha podido entender que don Quijote constituye para Cervantes y sus lectores «la piedra [de toque] de la verdad» y que su homólogo caballeresco don Diego no le va a la zaga en cuanto a «fortaleza», por utilizar el término canónico de Juan Ginés de Sepúlveda.

El pasaje «verdoso» y «oranés» trasluce por supuesto la controversia política y filosófica sobre las Armas y las Letras, pero sobre todo lo que está en juego «agora» es la cuestión de la nobleza de los miembros de la república («que unos [caballeros] son de oro, otros de alquimia» ${ }^{93}$ ) y la de «la defensa de los reinos» hispánicos ${ }^{94}$. Por si le quedaban dudas al discreto lector del momento, Cervantes le ha proporcionado antes algunas palabras liminares y programáticas en su prólogo: el soldado modélico -como él mismo se consideró en Lepanto- «más bien parece muerto en la batalla que libre en la fuga ${ }^{95}$. Frente a los leones africanos, podemos decir que don Quijote actuó, por lo tanto, de forma similar al joven Cervantes, cuyas «heridas», insiste en el mismo prólogo, deben guiar a los lectores «al cielo de la honra, y al de desear la justa alabanza» (II: 618). En cuanto a Orán, sus leones y el «humanismo de las Armas», acaso baste repetir las palabras de don Miguel: «Lo que va [en el carro] son dos bravos leones enjaulados, que el general de Orán envía a la corte, presentados a Su Majestad; las banderas son del rey nuestro señor, en señal que aquí va cosa suya» (II, 17: 762).

92. ... y si adoptamos la probable idea de Cervantes de que la Monarquía necesita bases militares en el Mediterráneo (África, Malta, el reino de Nápoles) para proteger sus fronteras meridionales $\mathrm{u}$ orientales contra los ataques de corso o de razia. Otras opciones eran posibles, como el abandono del presidio, a semejanza de lo que se va a hacer luego en Flandes.

93. Cervantes (1998, II, 6: 673).

94. Cervantes (1998, II, 1: 633).

95. Sobre el maquiavelismo de Cervantes respecto al tema de la lucha contra la Fortuna, léase Darnis 2016a: 151 («Dans cette séquence essentielle, Cervantès ne se contente pas d'inverser la situation qui avait placé don Quichotte dans une geôle à la fin de la Première partie, il crée aussi une forte analogie entre le gardien de lions et le chevalier au vert caban. Tous deux sont partisans d'un mode de vie prudent et d'une attitude qui évite tout risque, $c f$. Marquez Villanueva sur don Diego (2011: 177). Si la pensée politique de Machiavel n'est pas toujours chère au cœur de Cervantès, on observe dans le comportement de don Quichotte une même défense de la prise de risque, celle que notre auteur connut lorsqu'en particulier, il tenta sa première fuite d'Alger vers Oran à peine quatre mois et demi après son rapt au large des côtes européennes (janvier 1576). Il faut compter aussi sur ses multiples tentatives de fuite, qui ont dû forger chez Cervantès un esprit volontaire peu prompt à s'accommoder du pouvoir des pirates barbaresques. Or, la virtù (la vertu machiavélienne) exigeait précisément de ne jamais se plier au bon vouloir de la Fortune ( $c f$. Le prince, XXV); la sagesse de l'homme d'Etat réside, d'après Machiavel, dans sa capacité à faire reculer les frontières de ce que l'on nomme "nécessité" ou Fortune. L'historien florentin loue l'énergie de l'action plus que la prudence de la raison. La séquence des lions a donc une valeur essentielle dans la structure axiologique du livre de 1615. Elle permet à Cervantès de faire sien le point de vue de Machiavel et sa conclusion anti-aristotélicienne sur le courage des gouvernants: "qu'il vaut mieux être impétueux que circonspect", se plaisait à dire l'auteur italien»). 
Una cosa, sin embargo, queda incierta. Los aficionados a la secuencia recuerdan tal vez el desafío que lanzó hace más de veinte años Augustin Redondo: "¿Quién sabe si la manera de dirigirse a don Diego, por parte de don Quijote: "Señor galán", no encierra alguna alusión irónica a este contexto [donde prevalece el color verde de la vestimenta]?» (1998: 279). Puede que una última reflexión, esta vez de tipo intertextual, nos sirva para descubrir la alusión y comprender el enigma.

\section{SÉPTIMA OBSERVACIÓN: LA INTERTEXTUALIDAD}

Si antes de terminar este trabajo vamos a los posibles subtextos utilizados por Cervantes, surge uno que no solo completaría el cuadro antes esbozado, sino que además podría suministrar una clave necesaria de lectura.

El complejo armamento y el extraño atuendo del caballero verde delatan la parcialidad y animadversión que por él siente Cervantes. En efecto, los elementos tahalí, alfanje, de la jineta y, más sorprendente aún, la mezcla rara de los colores verde, morado y leonado dibujan un retrato muy similar al que se conoce de $\mathrm{Gazul}^{96}$. Este personaje, que formaba parte de los más conocidos del Romancero nuevo, era representativo de la literatura maurófila ${ }^{97}$.

96. Véanse, por ejemplo, los dos poemas siguientes:

VII: «Por la plaza de San Lúcar/galán paseando viene/ el animoso Gazul,/ de blanco, morado y verde./ Quiérese partir el moro/ a jugar cañas á Gelves/ que hace fiestas el alcalde/ por las treguas de los reyes./ Adora una bella mora,/ reliquia de los valientes/ que mataron en Granada/ los Zegríes y Gomeles $[\ldots] »$.

IX: «Cual bravo toro vencido/ que escarba la roja arena,/ de su Celinda afrentado,/ Gazul á San Lúcar deja./ Desesperado va el moro/ en una alazana yegua,/ con un jaez leonado,/ de su congoja la muestra./ En naranjado y en negro/ lo blanco y lo verde trueca,/ y lo amoroso morado/ en rabia cruel y negra./ Una marmota vestida/ de blanco y azul a medias,/ y en la parte que era azul /unas nubladas estrellas./ Listados van los volantes/ de encarnado y seda negra,/ el bonete azul escuro,/ cielo de luto y tristeza:/ solamente el tahalí/ del alfange verde lleva;/ porque él solo ha de vengarse/ de quien revuelve su esfera:/ y de la triste color/ que queda en la seca arena,/ el moro lleva la toca/ que el nervioso brazo aprieta:/ negritos son los borceguíes,/ y negras las estriberas:/ negras las ligas y cabos,/ y barcinas las espuelas:/ no lleva lanza alheñada,/ que ya la volara en piezas/ en la pared de su dama,/ cuando le cerró la puerta:/ lleva datilada adarga,/ y en ella una nueva seña,/ que es un ciclo escuro y triste/ en medio tina luna llena:/ llena, pero ya eclipsada,/ y alrededor esta letra:/ «Tan oscura como clara/y tan cruel como bella";/ y pues le quitó Celinda/ las alas con que alto vuela,/ no quiere plumas el moro/ en su gallarda cabeza [...].», citado por Galarreta Aima (2008: 63-68).

97. Ginés Pérez de Hita introdujo, por ejemplo, varios romances de este ciclo en Las guerras de Granada. Sobre el uso de un gabán «jironado», léase el trabajo de Gingras, que no saca conclusiones de tipo autobiográfico: «The second half of the fifteenth century witnessed a renewed attraction toward the exotic and colorful Arabic civilization. With this second wave of "maurofilia", the wearing of Moorish jirones again became stylish among the Christians. However, the long triangular inserts, formerly employed to give greater amplitude to the skirt of the sayo, had evolved into a purely decorative item. The jirones worn from the late fifteenth century onward now consisted of uniformlyshaped panels, or fajas placed over or sewn into the garment in order to create an impressive effect. Bernis confirms the widespread popularity of this later version of the jirones, mentioning examples of it in Italy, "en mujeres vestidas con influencia española". In fine, there is evidence of only two kinds of jirones in Spain. Both are of Moorish provenance. Given Cervantes' careful attention to 
Además del orientalismo temprano, la gracia de estas composiciones poéticas se debía a su trama sentimental. El ciclo poético protagonizado por Gazul contaba cómo el héroe celoso mata al marido de la hermosa Zaida de Jerez, de la que ha estado enamorado («Sale la estrella de Venus»). También narraban los romances que Gazul termina abandonando a Zaida por otra mujer ${ }^{98}$ : Celinda, a quien encuentra con motivo de las justas cortesanas de Gelves, en Andalucía («Por la plaza de Sanlúcar») ${ }^{99}$.

Augustin Redondo se había preguntado si no encerraría el personaje de don Diego alguna indirecta ${ }^{100}$. Creo dio en el clavo.

No es aventurado decir que algunos lectores debieron de pensar que el seudocaballero cervantino era una parodia del famoso paladín morisco ${ }^{101}$. Desde principios del siglo XVII, los romances nuevos sobre Gazul pronto fueron sometidos a una repetida labor de pastiche. Es así posible que Cervantes quisiera que algunos lectores pudieran pensar que don Diego aludiera a Lope de Vega ${ }^{102}$, quien habría disfrazado su propia historia sentimental bajo ropajes moriscos ${ }^{103}$. No es descabellado pensar que Cervantes tal vez se una

contemporary dress fashion throughout his works, I think it safe to conclude that it is the newer version of jirones, as decorative panels, which adorn Miranda's gabán» (1985: 139-140). También Bernis (1959). Zmanter propone en cualquier caso también una «Lecture morisque du Caballero del Verde Gabán» (1990: 343-353).

98. Gazul actúa como el don Quijote «desamorado» del seudo-Avellaneda...

99. Sobre el simbolismo de los colores de la vestimenta de Gazul, Galarreta Aima puntualiza lo siguiente: «Al mismo tiempo que se nos presenta una relación detallada de las vestimentas de Gazul (figura poética de la enumeración), el receptor además comprende que el cambio en la situación sentimental de Gazul siempre tiene un correspondiente en la variación de los colores de su ropa y armas. Estos adquieren, pues, un importante valor estético, ya que determinados colores como el verde, morado, amarillo y blanco asumen una carga simbólica positiva porque representan la alegría y la victoria amorosa frente a colores como el azul y el negro que simbolizan, en cambio, los celos y la tristeza» (2008: 16-17).

100. Redondo (1998: 279).

101. Ya en 1975, Percas de Ponseti señaló que, en el Caballero del Verde Gabán, varios indicios apuntaban a Lope de Vega (345-382). Los colores verde, morado y leonado solían hallarse desde 1495 en descripciones técnicas, no literarias como atributos de alta categoría, «solían ser tintos en lana y con costes muy elevados», recuerda Paulino Iradiel Murugarren (1974: 226).

102. La primera edición del Romancero general data de 1600. Sin aludir siempre al horizonte de expectativas de los lectores contemporáneos de Cervantes ni la obsesión cervantina por Lope de Vega (Pedraza Jiménez 2006), varias teorías fueron propuestas para percibir en don Diego de Miranda a alguna persona real: Astrana Marín recuerda a aquel Diego de Miranda encarcelado con Cervantes en Valladolid (1951: 359); Guerrero Hortigón sugirió en 1992 al extremeño Ruy González Quijada, señor de Valdepalacios; Barros Campos (1996), tras descartar a varios Diego de Miranda, se inclina por identificar al personaje cervantino con don Diego de Vargas León, natural de Arganda y descendiente del don Manuel de León citado en el artículo; en cuanto a Baras Escolá (2010), identifica al Caballero del Verde Gabán con don Alonso Ramírez de Prado, y a su hijo don Lorenzo con don Lorenzo Ramírez de Prado, ambos poetas, estudiantes en la Universidad de Salamanca y exégetas de pasajes dudosos de Marcial.

103. Según Goyri (1953), estos poemas en clave presentan las equivalencias siguientes: Gazul= Lope; Zaida = Marfisa; Celinda = Elena Osorio. No obstante, Lope había asumido, por cierto, varias identidades onomásticas aparte de Gazul y no está claro aún que los romances aducidos «Por la plaza de San Lúcar / galán paseando viene» y «Cual bravo toro vencido / que escarba la roja arena» fueran escritos por Lope; Antonio Sánchez Jiménez solo incluye el primero entre los auténticos de Lope (2015: 206-215). 
a las filas del escuadrón antilopesco con aquel «caballero del verde gabán». Sabemos así que, si bien ha procurado siempre evitar la sátira ad hominem, las cargas del grupo de Lope contra él y su primer Quijote le han sabido muy agrias ${ }^{104}$. Hasta tal punto que la Segunda parte, como la Primera, terminó también censurando al «tirano» de las tablas ${ }^{105}$. La defensa de la poesía como una «doncella que no quiere ser manoseada» delante de don Diego, alter ego del Fénix, no es a lo mejor una casualidad: «No ha de ser vendible», insisten don Quijote... y Cervantes (II, 16: 757) ${ }^{106}$. Si, por lo tanto, a buen entendedor, «pocas palabras» (II, 37: 938), lo cierto es que con el «señor galán» «del verde gabán», Cervantes sin duda mató dos pájaros de un solo tiro: al rey del imperio hispánico y al «monstruo» del teatro castellano.

\section{BIBLIOGRAFÍA CITADA}

Abi-Ayad, Ahmed (1998). «Orán: fuente literaria y lugar de escritura de Miguel de Cervantes», en María Cruz García de Enterría y Alicia Cordón Mesa (coords.), Actas del IV Congreso Internacional de la AISO, vol. 1. Alcalá de Henares: Universidad, pp. 117-126.

Abi-Ayad, Ahmed (2004). «Oran, l'Espagne et Cervantes», Insaniyat. 23-24, pp. 223-232. Alonso Acero, Beatriz (1997). Orán y Mazalquivir en la política norteafricana de España. Madrid: Universidad Complutense de Madrid (tesis de doctorado).

104. Pedraza (2006); Darnis (2016c). Para Álvarez, «non seulement don Quichotte connaît dans cet épisode une nouvelle naissance, mais il semble rejeter en même temps, avec une ironie pleine de sarcasme, l'idéal de vie décrit par Mosén Valentín au chapitre 7 de la continuation apocryphe, avec lequel la vie bien réglée de don Diego de Miranda présente certains points communs» (la nota cita este pasaje del libro apócrifo: «Por tanto, señor Quijada, por la pasión que Dios pasó, le ruego que vuelva sobre sí y deje esta locura en que anda, volviéndose a su tierra; y pues me dice Sancho que tiene razonablemente hacienda, gástela en servicio de Dios y en hacer bien a pobres, confesando y comulgando a menudo, oyendo cada día su misa, visitando enfermos, leyendo libros devotos y conversando con gente honrada y, sobre todo, con los clérigos de su lugar, que no le dirán otra cosa que la que le digo»). Para mi colega, «Ce rejet s'exprime lors de la critique des chevaliers courtisans qui, selon le héros, sont dépourvus de vrai courage: "Mejor parece, digo, un caballero andante socorriendo a una viuda en algún despoblado que un cortesano caballero requebrando a una doncella en las ciudades [...] en esto de acometer aventuras, créame vuesa merced, señor don Diego, que antes se ha de perder por carta de más que de menos, porque mejor suena en las orejas de los que oyen 'el tal caballero es temerario y atrevido' que no 'el tal caballero es tímido y cobarde" [ $\ldots .$. . Or, ces chevaliers courtisans ont précisément le beau rôle dans le texte du continuateur, en particulier à Saragosse et à Madrid» (2010: 304-305).

105. Darnis (2016a: 140-141): «Il semble en outre qu'à travers la référence au héros morisque, Cervantès vise plus largement l'héroïsme frelaté. Gazul a en effet pour tout ennemi un mari vieillissant (celui de Zaida) et des concurrents de foire: à l'instar d'Álvaro de Tarfe dans le Segundo tomo du pseudo-Avellaneda, le chevalier morisque mesure la force de son bras aux seuls combats des cañas de Gelves. Pire, il n'a d'autre combat à mener que de mettre en pièce l'effigie de ses belles ("Quitó al caballo el jaez, / y la empresa de su dama, / como si fuese león, / con los dientes despedaza"). À ce compte, il va sans dire que, bien que touché par la folie, don Quichotte est un être bien plus valeureux que son double de pacotille -l'homme au caban vert-, dont le prestige chevaleresque se limite à être une pâle copie d'un hérö̈sme lopesque, lui-même factice».

106. Percas de Ponseti (1975: 361-381); Darnis (2016a: 140-141). 
Alonso Acero, Beatriz (2012). «Orán, ciudad de frontera», en Ismet Terki-Hassainé, Emilio Sola Castaño y Alejandro R. Díez Arboniés (coords.), Las campanas de Orán (1509-2009). Alcalá de Henares: Servicio de publicaciones.

Álvarez, Josefa (2007). «El caballero del Verde Gabán: algunas consideraciones desde el epicureísmo y el estoicismo», Anales Cervantinos. 39, pp. 147-158. https://doi. org/10.3989/anacervantinos.2007.005.

Álvarez Roblin, David (2010). Pratique de l'apocryphe dans le roman espagnol du debut du XVIIe siècle: approche comparée du Guzmán de Luján et du Quichotte d'Avellaneda. Burdeos: thèse de doctorat.

Aristóteles (1985). Ética nicomáquea. Gredos: Madrid.

Astrana Marín, Luis (1951). Vida ejemplar y heroica de Miguel de Cervantes Saavedra, vol. 7. Madrid: Reus.

Baras Escolá, Alfredo (2010). «Don Diego Miranda y su hijo don Lorenzo, discretos caballeros de la Mancha», en María Carmen Marín Pina (ed.), Cervantes en el espejo de su tiempo. Zaragoza: Universidad, pp. 61-88.

Barros Campos, José (1996). «Un madrileño, Caballero del Verde Gabán», Anales del Instituto de Estudios Madrileños. 36, pp. 441-451.

Bernis, Carmen (1959). «Modas moriscas en la sociedad cristiana española del siglo XV», Boletín de la Real Academia de la Historia. 144, pp. 199-236.

Borges, Jorge Luis (1998). Ficciones. Madrid: Alianza Editorial.

Bunes Ibarra, Miguel Ángel (2006). «La defensa de la cristiandad: las Armadas en el Mediterráneo en la edad moderna», Cuadernos de Historia Moderna. Anejos (V), pp. 77-99.

Bunes Ibarra, Miguel Ángel de (2011). «Diego Suárez Montañés, cronista y testigo de la historia de Orán-Mazalquivir», en Miguel Ángel de Bunes Ibarra y Beatriz Alonso Acero (coords.), Orán: historia de la Corte Chica. Madrid: Polifemo, pp. 323-368.

Cabrera de Córdoba, Luis (1998). Felipe II: rey de España. Valladolid: Junta de Castilla y León.

Carvallo, Luis Alfonso de (1997). Cisne de Apolo. Kassel: Reichenberger.

Cascardi, Anthony (2012). Cervantes, Literature and the Discourse of Politics. Toronto: PU.

Castilla Urbano, Francisco (2013). El pensamiento de Juan Ginés de Sepúlveda: vida activa, humanismo y guerra en el Renacimiento. Madrid: Centro de Estudios Políticos y Constitucionales.

Cervantes, Miguel de (1835). Don Quijote, ed. Diego Clemencín. Madrid: D. E. Aguado.

Cervantes, Miguel de (1998). Don Quijote, coord. Francisco Rico. Barcelona: Crítica.

Cervantes, Miguel de (2014). La Galatea, coord. Juan Montero. Madrid: RAE.

Cervantes, Miguel de (2015). Comedias y tragedias, coord. Luis Gómez Canseco. Madrid: RAE, 2 vols.

Chaulet, Rudy y Olga Ortega (2013). "Le rachat de captifs espagnols à Alger au XVIe siècle. Le cas de la rédemption de Diego de Cisneros (1560-1567)», Cahiers de la Mediterrannée, pp. 187-200. Accesible en: <https://journals.openedition.org/ $\mathrm{cdlm} / 7232>$.

Close, Anthony (2007). Cervantes y la mentalidad cómica de su tiempo. Alcalá de Henares: CEC.

Darnis, Pierre (2015a). Don Quijote: éléments sur une satire ménippéenne. Neuilly: Atlande.

Darnis, Pierre (2015b). «Lecture publique - Lecture solitaire: deux paramètres déterminants dans les comportements herméneutiques du lecteur moderne (le cas du récit cervantin)», en Nicolas Correard, Vincent Ferré y Anne Teulade (coords.), L'herméneutique fictionnalisée: quand l'interprétation s'invite dans la fiction. París: Garnier, pp. 35-52. 
Darnis, Pierre (2015c). «Prosas nuevas (cartas, relaciones, Lazarillos, Guzmanes y Quijotes -I-). Para una lectura «superficial» (y esencial) de La vida de Lazarillo de Tormes, $y$ de sus fortunas y adversidades», en Elvezio Canonica y Cristina Panzera (coords.), La Lettre au carrefour des genres et des traditions du Moyen Âge au XVIIe siècle. París: Garnier, pp. 257-286.

Darnis, Pierre (2016a). «Segunda parte de Don Quijote de la Mancha: éléments sur une satire ménippéenne (II)», en Ficciones de Jorge Luis Borges - Segunda parte de Don Quijote, de Cervantès. Neuilly: Atlande, pp. 69-236.

Darnis, Pierre (2016b). «Les chapitres 1-10 de la Segunda parte del ingenioso caballero don Quijote de la Mancha, ou les bases du récit ménippéen et de sa lecture», e-Spania. 23. Accesible en: <https://e-spania.revues.org/25300>.

Darnis, Pierre (2016c). «Tramas del Quijote (V): los duques y la vara de medir de Cervantes: la culpabilización de segundo nivel en la Segunda parte de Don Quijote», en Pedro Ruiz Pérez (coord.), Cervantes: los viajes y los días. Córdoba: Prosa BarrocaSIAL, pp. 181-223.

Darnis, Pierre (2018). «La trama primera de la Segunda parte y el viaje a Zaragoza (Tramas del Quijote - II-)», Esferas literarias. 1. Accesible en: <http://www.uco.es/ ucopress/ojs/index.php/Esferas/index>.

Domínguez Ortiz, Antonio (1985). Las clases privilegiadas del Antiguo Régimen. Madrid: Istmo.

Fernández Izquierdo, Francisco (1992). «Discurso sobre el ejercicio militar de las órdenes militares para defensa de las costas de África (ca. 1610)», en Julio Pardos Martínez, Julián Viejo Yharrassarry, José María Iñurritegui Rodríguez, José María Portillo Valdés y Fernando Andrés Robres (coords.), Historias en fragmentos: estudios en homenaje a Pablo Fernández Albaladejo. Madrid: UAM, pp. 233-245.

Fradejas Lebrero, José (2008). Más de mil y un cuentos del Siglo de Oro. Madrid-Frankfurt: Iberoamericana-Vervuert.

Fuentes Vázquez, Manuel (2007). «Del donoso escrutinio (Menard y Unamuno): revisión de una hipótesis», en Matías Barchino Pérez (coord.), Territorios de la Mancha. Versiones y subversiones cervantinas en la literatura hispanoamericana. Cuenca: Universidad.

Galarreta Aima, Diana F. (2008). Construcción idealizada de la figura del moro. Lima: Universidad Pontificia (tesis de doctorado).

Garcés, María Antonia (2005). Cervantes en Argel. Madrid: Gredos.

García-Arenal, Mercedes y Miguel Ángel Bunes Ibarra (1992). Los españoles y el norte de África (siglos $X V$-XVIII). Madrid: Mapfre.

Ginés de Sepúlveda, Juan (2003). «Exhortación a Carlos V», en Obras Completas, vol. 7, ed. J. M. Rodríguez Peregrina. Pozoblanco: Excmo. Ayuntamiento de Pozoblanco.

Ginés de Sepúlveda, Juan (2012). Diálogo llamado Demócrates. Madrid: Tecnos.

Gingras, Gerald L. (1985). «Diego de Miranda, "Bufón” or Spanish Gentleman? The Social Backround of his Attire», Cervantes. 5 (2), pp. 129-140.

Gonzalo Sánchez-Molero, José Luis (2010). La Epistola a Mateo Vázquez: historia de una polémica literaria en torno a Cervantes. Alcalá de Henares: CEC.

Goyri de Menéndez Pidal, María (1953). «Los romances de Gazul», Nueva Revista de Filología Hispánica. 7, pp. 403-416.

Guerrero Hortigón, Luis (1992). El Caballero del Verde Gabán. Córdoba: Graficromo.

Hartog, François (2003). Régimes d'historicité. Présentisme et expériences du temps. París: Éditions du Seuil.

Higuera, Henry (1995). Eros and Empire: Politics \& Christianity in Don Quixote. Lanham: Rowman \& Littelfield Publishers.

Insua Rodríguez, Pedro (2017). Guerra y paz en el Quijote. Madrid: Encuentro. 
Iradiel Murugarren, Paulino (1974). Evolución de la industria textil castellana en los siglos XIII-XVI. Salamanca: Universidad de Salamanca.

Jiménez Moreno, Agustín (2011). Nobleza, guerra y servicio a la Corona: los caballeros de hábito en el siglo XVII. Madrid: UCM (tesis de doctorado).

Koselleck, Reinhart (1990). Le futur passé: contribution à la sémantique des temps historiques. París: EHESS.

Layna Ranz, Francisco (2005). La eficacia del fracaso: representaciones culturales en la segunda parte del Quijote. Madrid: Polifemo.

Liang, Yuen-Gen (2011). Family and Empire: The Fernandez de Cordoba and the Spanish Realm. Filadelfia: PU.

López Pinciano, Alonso (1998). Philosophia antigua poética. Madrid: Fundación José Antonio de Castro.

Malcolm, Noel (2016). Agentes del Imperio: caballeros, corsarios, jesuitas y espías en el Mediterráneo del siglo XVI. Barcelona: Galaxia Gutenberg.

Mármol Carvajal, Luis (1573). Libro tercero y segundo volumen de la Primera parte de la descripción general de África. Granada: Rabut.

Márquez Villanueva, Francisco (2010). Moros, moriscos y turcos de Cervantes: ensayos críticos. Barcelona: Bellaterra.

Márquez Villanueva, Francisco (2011). Personajes y temas del Quijote. Barcelona: Bellaterra.

Martín Corrales, Eloy (2008). «La defensa de las costas, del tráfico marítimo y de los súbditos frente al corso musulmán en la España de la Edad Moderna», en Francisco Morales Padrón (coord.), XVII Coloquio de Historia Canario-Americana. V Centenario de la muerte de Cristóbal Colón. Las Palmas de Gran Canaria: Cabildo insular de Gran Canaria, pp. 1854-1882.

Martínez Góngora, Mar (2013). «Más allá del Islam: África en Don Quijote», eHumanista/Cervantes. 2, pp. 362-378.

Martínez Mata, Emilio (2015). «El caballero del Verde Gabán como modelo de vida», Monteagudo. 20, pp. 73-103.

Martínez Torres, José Antonio (2004). Prisioneros de los infieles: vida y rescate de los cautivos cristianos en el Mediterráneo musulmán (siglos XVI-XVIII). Barcelona: Bellaterra.

Moner, Michel (1986). Cervantès: deux thèmes majeurs (l'amour-les armes et les lettres). Toulouse: France-Ibérie Recherche.

Navarro Ledesma, Francisco (1960). El ingenioso hidalgo don Quijote de la Mancha. Madrid: Espasa-Calpe.

Pedraza Jiménez, Felipe B. (2006). Cervantes y Lope: historia de una enemistad y otros estudios cervantinos. Barcelona: Octaedro.

Percas de Ponseti, Helena (1975). Cervantes y su concepto del arte: estudio crítico de algunos aspectos y episodios del Quijote. Madrid: Gredos.

Redondo, Augustin (1998). Otra manera de leer el Quijote: historia, tradiciones culturales y literatura. Madrid: Castalia.

Reichenberger, Kurt (2005). Cervantes and the hermeneutics of satire. Kassel: Reichenberger.

Rodríguez Salgado, María José (2004). Felipe II, el "Paladín de la Cristiandad" y la paz con el Turco. Valladolid: PU.

Sáez, Adrián J. (2018). «Una vida en el margen: la relación soldadesca de Suárez Montañés», en Eva María Flores Ruiz y Fernando Durán López (coords.), Guerras de soledad, soldados de infamia: representaciones de combatientes irregulares, clandestinos o mercenarios en la literatura española. Palma de Mallorca: Genueve ediciones. 
84 - PIERRE DARNIS

Sliwa, Krzysztof (2006). Vida de Miguel de Cervantes Saavedra. Kassel: Reichenberger.

Vega y Carpio, Lope (2015). Romances de juventud, Antonio Sánchez Jiménez (ed.). Madrid: Cátedra.

Viaje de Turquía (anónimo) (2010). Madrid: Cátedra.

Zmanter, Françoise (1990). «Lecture morisque du Caballero del Verde Gabán dans le Don Quichotte de Cervantès», en Abd al-Galil al (ed), Métiers, vie religieuse et problématiques d'histoire morisque. Zaghouan: Ceromdi, pp. 343-353.

Recibido: 20 de octubre de 2018

Aceptado: 24 de julio de 2019 